LA-13628-MS

Approved for public release;

distribution is unlimited.

\title{
Confinement Vessel Dynamic Analysis
}
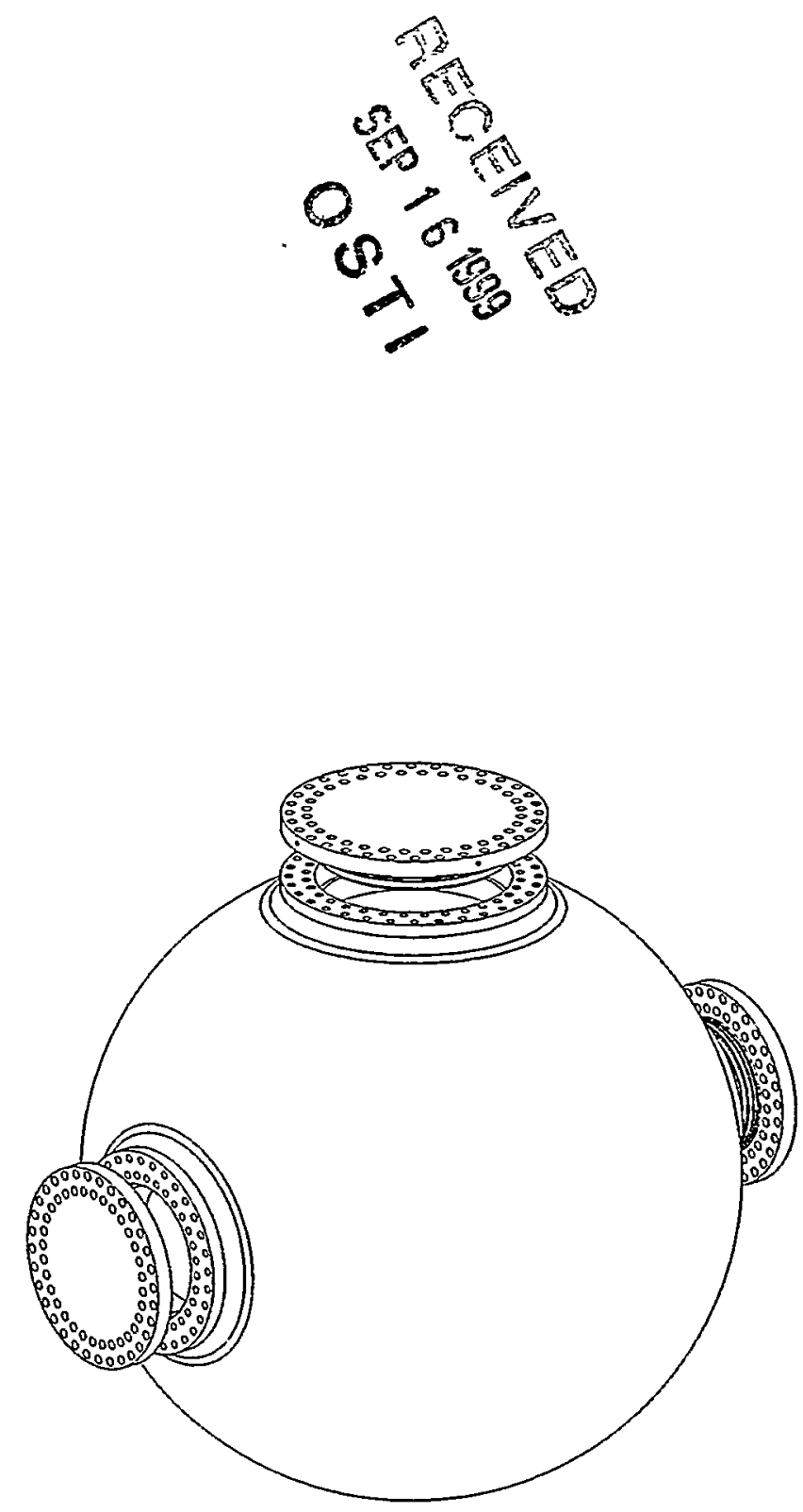

\section{Los Alamos \\ NATIONAL LABORATORY}

Los Alamos National Laboratory is operated by the University of California for the United States Department of Energy under contract W-7405-ENG-36. 
An Affirmative Action/Equal Opportunity Employer

This report was prepared as an account of work sponsored by an agency of the United States Government. Neither The Regents of the University of California, the United States

Government nor any agency thereof, nor any of their employees, makes any warranty, express or implied, or assumes any legal liability or responsibility for the accuracy, completeness, or usefulness of any information, apparatus, product, or process disclosed, or represents that its use would not infringe privately owned rights. Reference herein to any specific commercial product, process, or service by trade name, trademark, manufacturer, or otherwise, does not necessarily constitute or imply its endorsement, recommendation, or favoring by The Regents of the University of California, the United States Government, or any agency thereof. The views and opinions of authors expressed herein do not necessarily state or reflect those of The Regents of the University of California, the United States Government, or any agency thereof. Los Alamos National Laboratory strongly supports academic freedom and a researcher's right to publish; as an institution, however, the Laboratory does not endorse the viewpoint of a publication or guarantee its technical correctness. 


\section{DISCLAIMER}

\section{Portions of this document may be illegible in electronic image products. Images are produced from the best available original document.}




\title{
Confinement Vessel Dynamic Analysis
}

\author{
R. Robert Stevens
}

Stephen P. Rojas 


\section{Table of Contents}

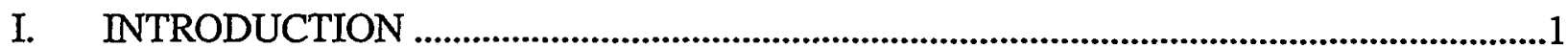

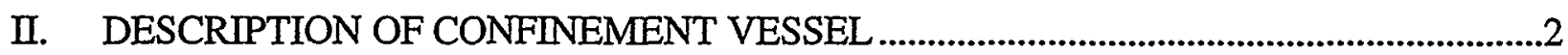

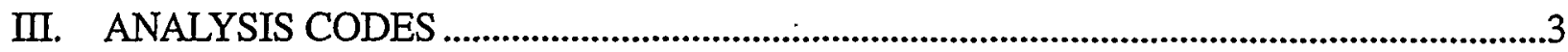

a) Hydrodynamic Codes ..........................................................................................................

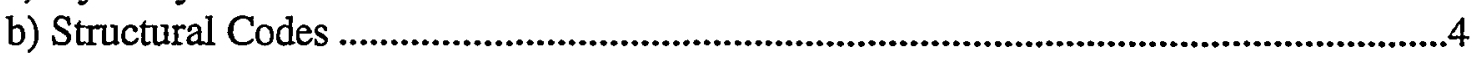

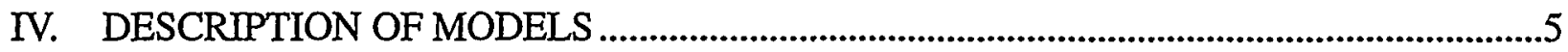

a) Hydrodynamic Models, Axisymmetric Analyses.....................................................5

b) Hydrodynamic Models, Three-Dimensional Analysis ...............................................6

c) Structural Models, Simplified Ports............................................................................6

d) Structural Models, Detailed Ports...........................................................................................7

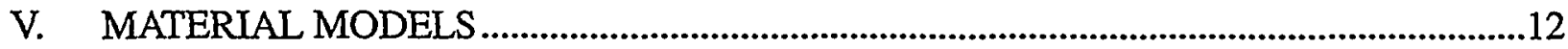

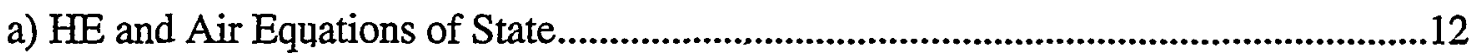

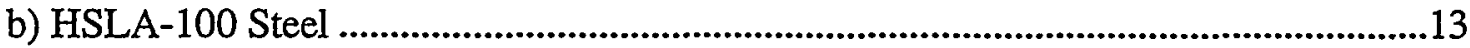

VI. COUPLING OF HYDROCODE AND STRUCTURAL ANALYSES ..............................14

a) Assignment of Applied Pressures .....................................................................................14

b) Adjustment of Applied Pressures for Zero Net Impulse ...............................................15

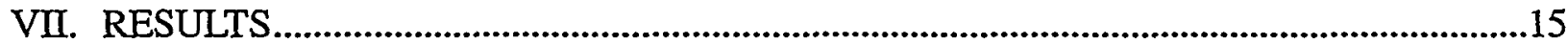

a) Outline of All Analyses .....................................................................................................15

b) Description of Vessel Response.........................................................................................15

c) Applied Pressures, Center Initiation ...................................................................................17

d) Applied Pressures, Off-Center Initiation ..........................................................................19

e) Comparison of LS-DYNA and PARADYN Results .....................................................21

f) Peak Stresses in Vessel....................................................................................................22

g) Effect of Vessel Support Stand .............................................................................................25

h) Slip and Gap at O-Ring Seals .......................................................................................26

i) Bolt Loading .........................................................................................................................27

VIII. COMPARISONS TO EXPERIMENTAL TESTS .............................................................27

IX. ANALYSIS OF MODELING ERRORS …......................................................................29

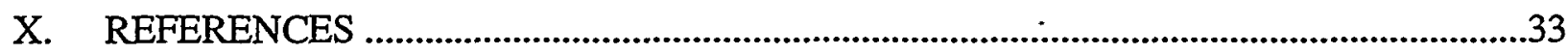




\title{
Confinement Vessel Dynamic Analysis
}

\author{
R. Robert Stevens \\ Stephen P. Rojas
}

\begin{abstract}
A series of hydrodynamic and structural analyses of a spherical confinement vessel has been performed. The analyses used a hydrodynamic code to estimate the dynamic blast pressures at the vessel's internal surfaces caused by the detonation of a mass of high explosive, then used those blast pressures as applied loads in an explicit finite element model to simulate the vessel's structural response. Numerous load cases were considered. Particular attention was paid to the bolted port connections and the $O$-ring pressure seals. The analysis methods and results are discussed, and comparisons to experimental results are made.
\end{abstract}

\section{INTRODUCTION}

A series of hydrodynamic and structural analyses of a 72-in. (inside diameter) spherical confinement vessel has been performed using a combination of two numerical techniques. The transient pressures acting on the inner surfaces of the vessel were computed using an Eulerian hydrodynamics code, which simulated the burn of the high explosive (HE) and the internal gas dynamics. The vessel's structural response to these pressures was then analyzed using an explicit finite element structural dynamics code.

The simulation required the use of large, detailed meshes to accurately simulate the vessel's dynamic response. Particular attention was paid to representing the effect of various engineering features such as the bolted port connections. The modeling techniques and assumptions that were made in the analyses are discussed, and some of the most important results will be presented, including the estimates of the blast pressures applied to the vessel walls, the dynamic stress and strain at several key locations, the magnitude of relative motion across the vessel's door-to-nozzle bolted interfaces, and the dynamic loads carried by the door-to-nozzle bolts themselves.

A series of tests of the confinement vessels has recently been completed. Various strain measurements were recorded during these tests; this experimental data will be compared to the corresponding results from the models. 


\section{DESCRIPTION OF CONFINEMENT VESSEL}

The confinement vessel under consideration is identified by its drawing number, 47Y-115576. It is a spherical vessel with three access ports: two 16-in. ports on the "beam axis" and a single 22 -in. port at the top "north pole" of the vessel. The vessel is shown in Fig. 1, with the coordinate system used for all models.

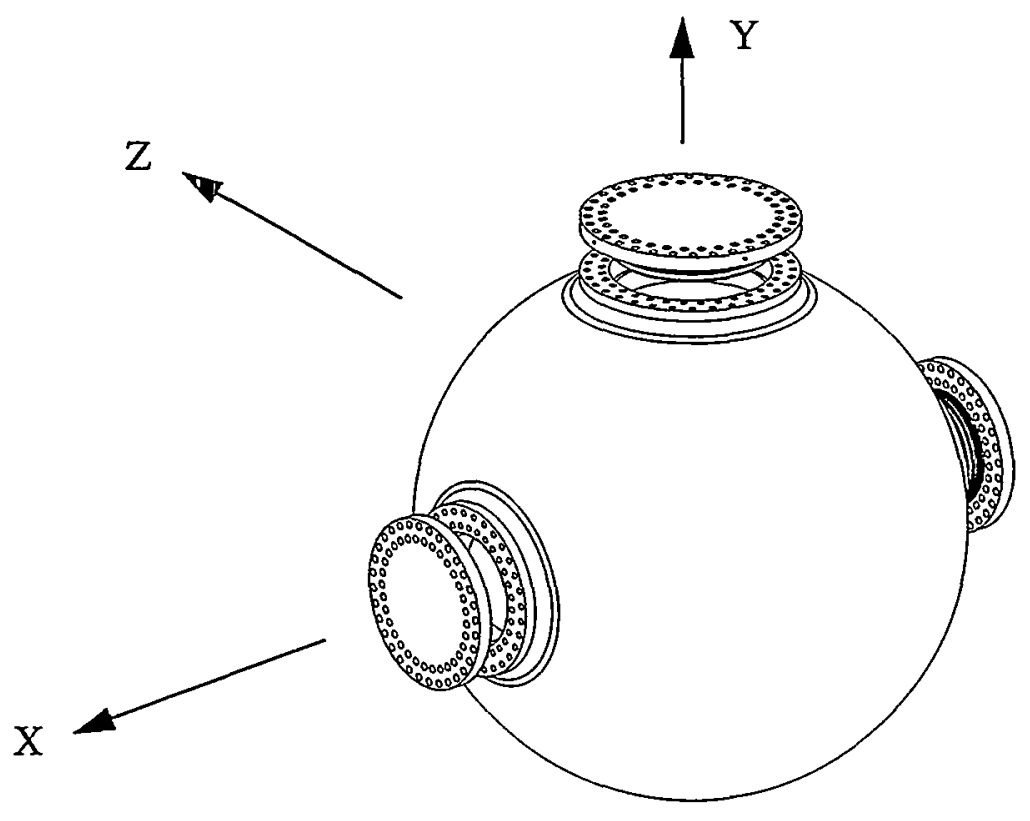

Fig. 1. Confinement vessel, with coordinate system.

The vessel has an inside diameter of $72 \mathrm{in.}$ and a $2 \mathrm{in.} \mathrm{(nominal)} \mathrm{wall} \mathrm{thickness.} \mathrm{The} \mathrm{vessel} \mathrm{is}$ fabricated from a steel designated HSLA-100, which was chosen primarily for its high strength, high fracture toughness, and no requirement for postweld heat treatment. The vessel walls are made from rolled plate, but the nozzles and doors are forgings.

The vessel's three large access ports must maintain a seal during use to prevent any release of gases or material to the external environment. Each door is connected to the vessel with 64 highstrength bolts, and four separate seals at each door ensure a positive pressure seal. As shown in Fig. 2, there is one O-ring on the main mating surface between the door and nozzle and two Orings on the tapered "piston" section of the door. There is also one metal seal (seal "D") on the "shoulder" of the door. 


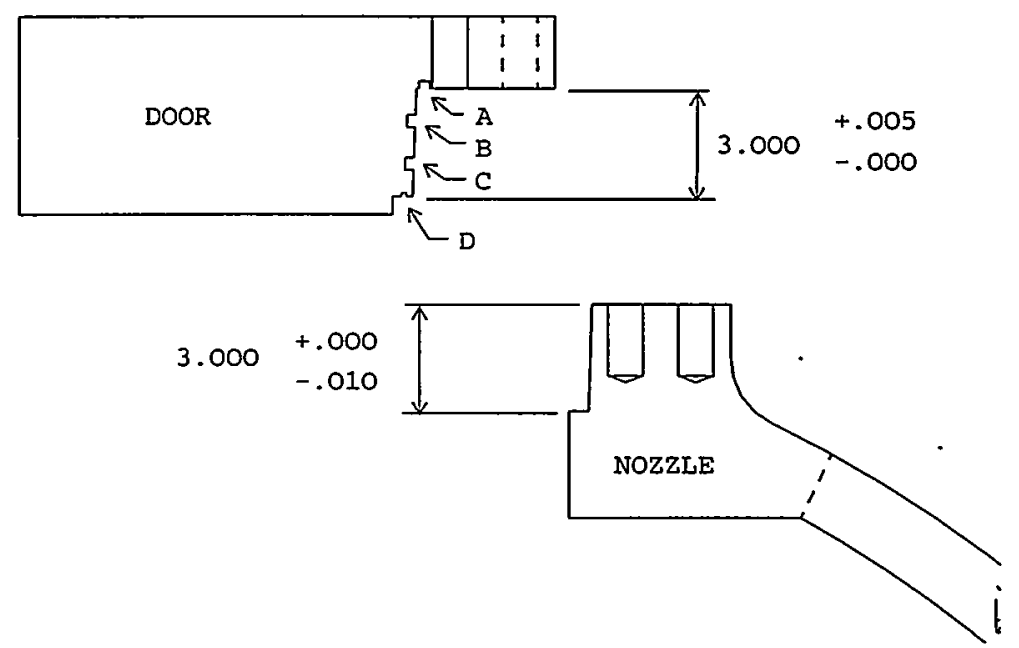

Fig. 2. The four O-ring grooves for the pressure seals between each door and nozzle of the confinement vessel.

\section{ANALYSIS CODES}

\section{a) Hydrodynamic Codes}

The simulations of the HE burn and estimates of the transient pressures acting on the inner surfaces of the vessel were made using the Eulerian hydrodynamic analysis codes MESA2D [1] and $\mathrm{CTH}[2,3]$. MESA2D and CTH replace the conservation equations of mass, energy, and momentum with finite difference or finite volume approximations in order to model multidimensional, multimaterial problems that are characterized by large deformations or strong shocks. Both codes use a two-step Lagrangian-Eulerian solution scheme during which the distorted mesh from the Lagrangian step (mass, momentum, energy, and strength variables) is remapped back to the original Eulerian mesh that is fixed in space. For the purposes of the present analysis, both 2$\mathrm{D}$ and 3-D hydrodynamic calculations were performed; however, only the 2-D half- and fullmodel pressure-time results were passed on to the structural analysis code to be used as applied loads.

CTH uses a parallization method that breaks the mesh into subdomains; this is accomplished through a simple algorithm that attempts to make the work per processor constant and minimize the message size. For a typical 2-D axisymmetric run using 320,000 cells and 126 computational sub-domains, CPU time is approximately six hours (for a simulation time of $4.5 \mathrm{~ms}$ ) using the ASCI (Advanced Strategic Computing Initiative) Blue Mountain computer. 


\section{b) Structural Codes}

The simulation of the structural response used an explicit finite element code called PARADYN. PARADYN is a massively parallel version of DYNA3D [4], a nonlinear, explicit, Lagrangian finite element analysis code for three-dimensional transient structural mechanics. PARADYN was chosen because of DYNA3D's reputation and history and for its ability to handle very large models by efficiently using the available computational resources. PARADYN was run on numerous (32-504) processors of Blue Mountain, a connected array of independent SGI (Silicon Graphics, Inc.) computers.

PARADYN uses a "domain decomposition" parallization scheme to divide the mesh into parts so that the computational work is divided among the processors available on the computer. The mapping of one of the meshes that were used in the analyses into 504 computational domains is shown in Fig. 3. In this figure, the mesh takes advantage of two planes of symmetry, so that onequarter of the vessel is explicitly modeled. The total size of the quarter symmetry model was approximately one million elements, which can be handled on the Blue Mountain computer in about six hours of run time. The same analyses would have taken about 35 days when run on a single processor.

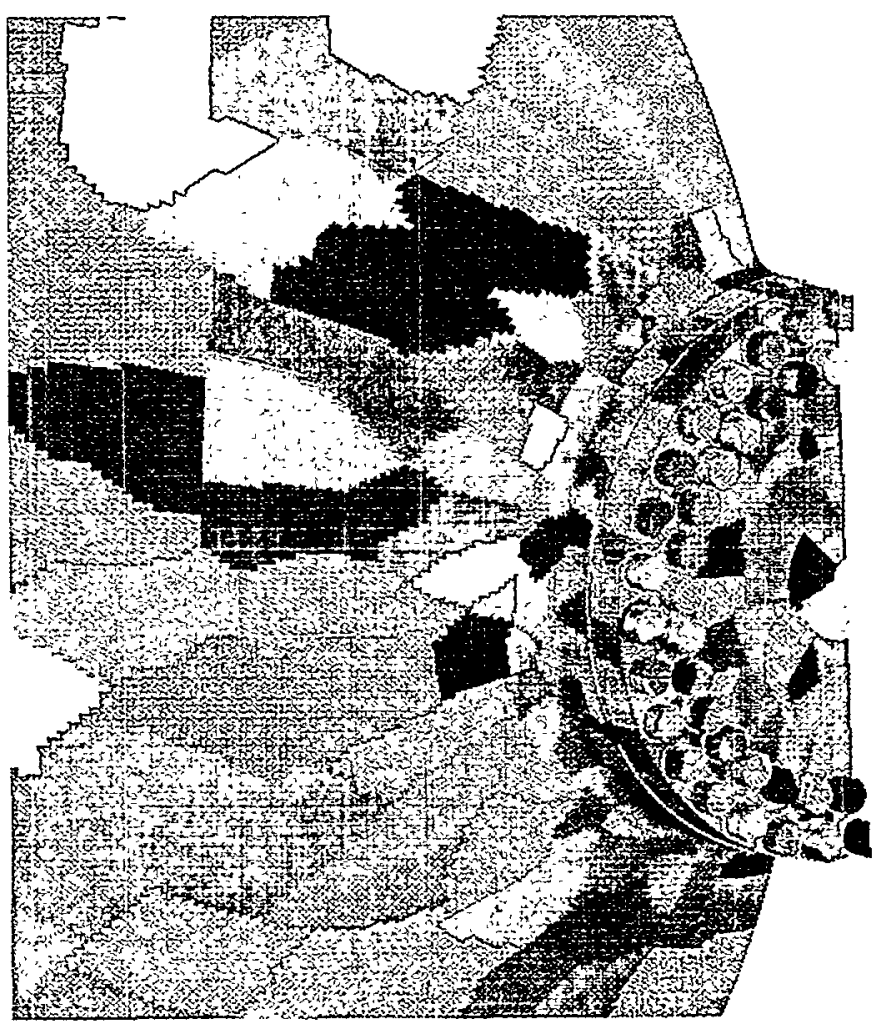

Fig. 3. Domain decomposition of one of the meshes used in the vessel structural analysis. 


\section{DESCRIPTION OF MODELS}

The simulations required the use of large, detailed meshes to accurately represent the dynamic response of the vessel and to adequately resolve the stresses and discontinuities caused by various engineering features of the vessel such as the bolts connecting the doors to their nozzles. All structural meshes consisted entirely of hex elements (shell elements were not used), and special attention was given to the nozzle regions where the highest stresses were thought to occur. Six hex elements were used through the 2 -in. wall thickness to accurately simulate the bending behavior of the vessel walls.

Several different meshes were used in the analysis of the confinement vessels. The choice of mesh depended on the level of detail required for each particular analysis and the amount of symmetry that could be exploited. Each mesh is described below.

\section{a) Hydrodynamic Models, Axisymmetric Analyses}

Figures 4 and 5 illustrate the 2-D half and full models that were used for determining the pressure time history applied to the vessel. In each case, the vessel was modeled as a perfect 36-in. radius sphere with a thickness of $2 \mathrm{in}$. For the noncenter-initiated studies, the 2-D full model was used with initiation points on the plane of symmetry. Based on a parametric meshing study, a mesh size of $0.25 \mathrm{~cm} / \mathrm{cell}$ was found to be a conservative value that successfully reproduced test results while minimizing CPU time.

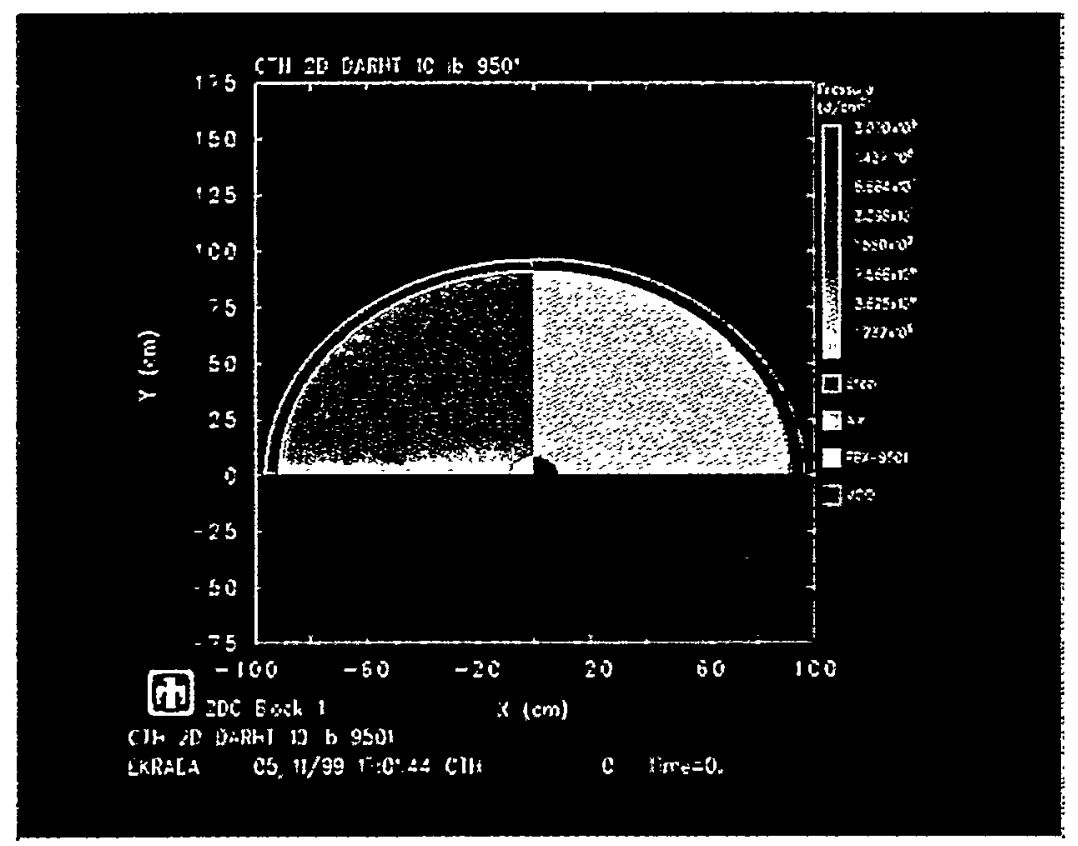

Fig. 4. The 2-D (half) axisymmetric model used for computing the pressure-time histories for the center-initiation load cases. 


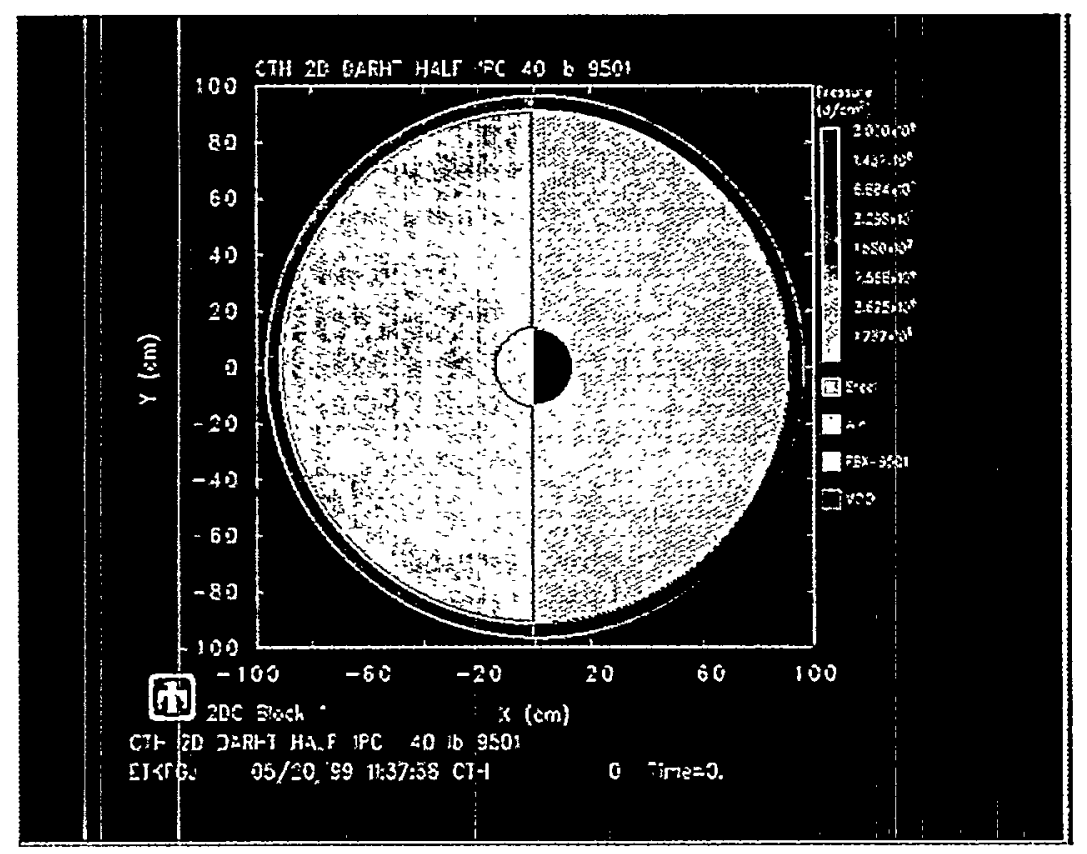

Fig. 5. The 2-D (full) axisymmetric model used for computing the pressure-time histories for the off-center-initiation load cases.

\section{b) Hydrodynamic Models, Three-Dimensional Analysis}

Figure 6 shows the three-dimensional model that included the effect of the 16-in. and 22-in. ports on the vessel wall loading. A mesh size of $1 \mathrm{~cm}$ per cell was used for both the $3-\mathrm{D}$ full and half models.

\section{c) Structural Models, Simplified Ports}

A family of analyses was run using meshes that did not allow any opening or slipping of the port doors relative to their nozzles. In these analyses, the bolted connections were assumed to have no slip or gap. The intent of these analyses was to make an initial estimate of the vessel response and investigate a wide range of load cases and vessel configurations, including the vessel support stand effects and nonsymmetric HE initiation effects. This family of meshes is referred to as the "v" series.

The simplest version of the model is shown in Fig. 7. In this model, the vessel is assumed to be "freely floating" in space-there are no external boundary conditions, and the stand on which the vessel sits was not modeled.

In order to verify that interaction with the vessel's support stand did not cause significant stresses during the dynamic response of the vessel, a variant of this analysis was made that used the same vessel model described above, but also included a representation of the support stand. Cylindrical 


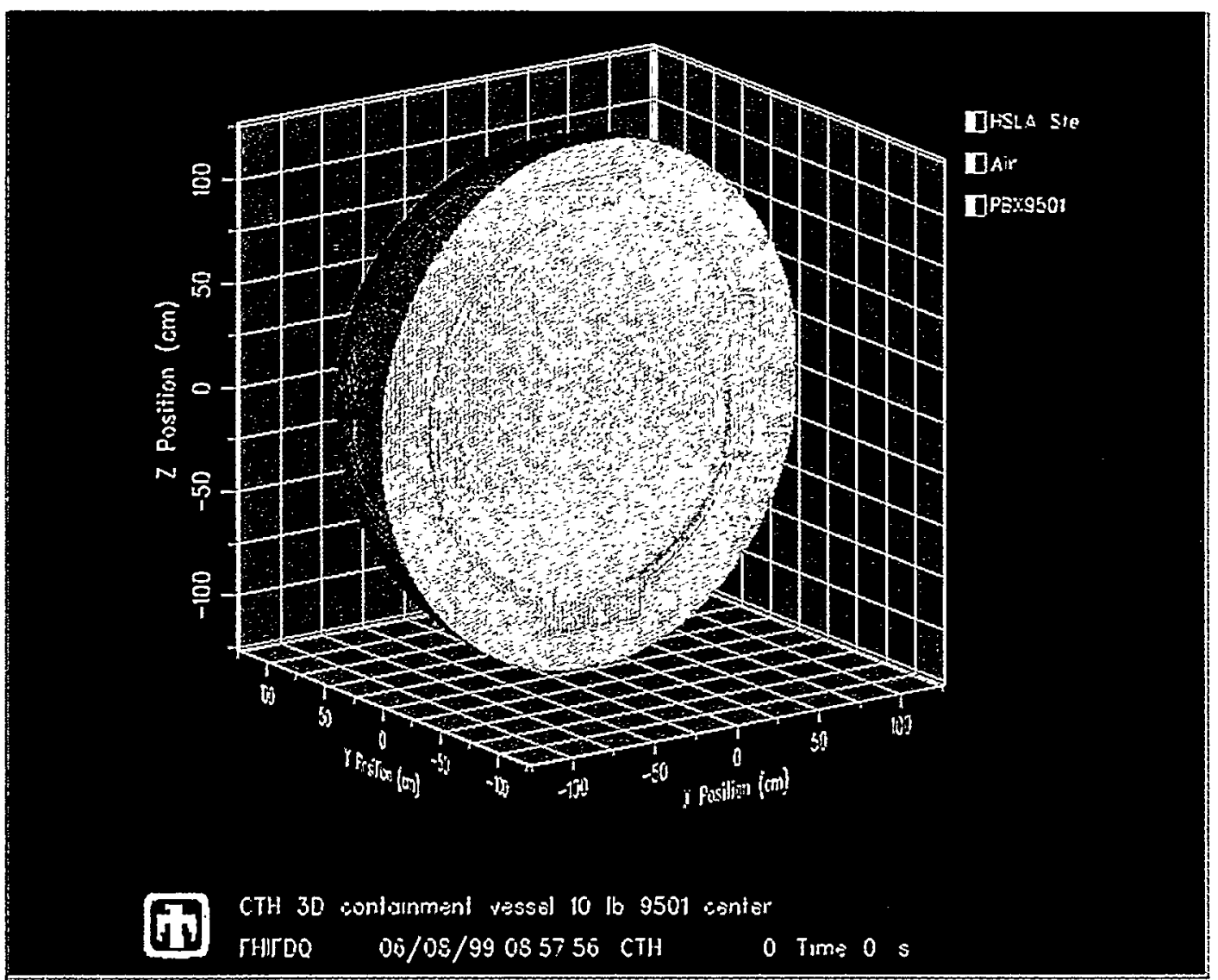

Fig. 6. The 3-D model, which allowed a true representation of both the 16-in. and 22-in. ports.

support bolts contact the 16-in. nozzles on both sides of the vessel. The mesh used for the support stand is shown in Fig. 8.

For all of the center-detonated spherical HE charges, a one-quarter symmetry model was sufficient to represent the whole vessel. However, one load case that was considered used an off-center initiation point. This load case required the use of a half-symmetry model. Figure 9 shows a schematic diagram of this vessel/HE configuration and shows the numbering scheme used to identify the tracer points.

\section{d) Structural Models, Detailed Ports}

An additional set of analyses, using different meshes, was conducted to investigate the amount of deformation between the doors and nozzles, to investigate the potential for slip or opening between the doors and their nozzles, and to estimate the bolt loading caused by the blast pressures and the vessel response. The model used in these analyses had a very high mesh density and explicitly modeled the bolts that connect the doors to their nozzles. Each door was connected to its nozzle with 64 high-strength bolts, which were individually modeled in order to accurately predict the amount of slip between the door and the nozzle and ensure that the amount of elastic deformation of the parts was within the allowable range for the O-ring seals to maintain the 


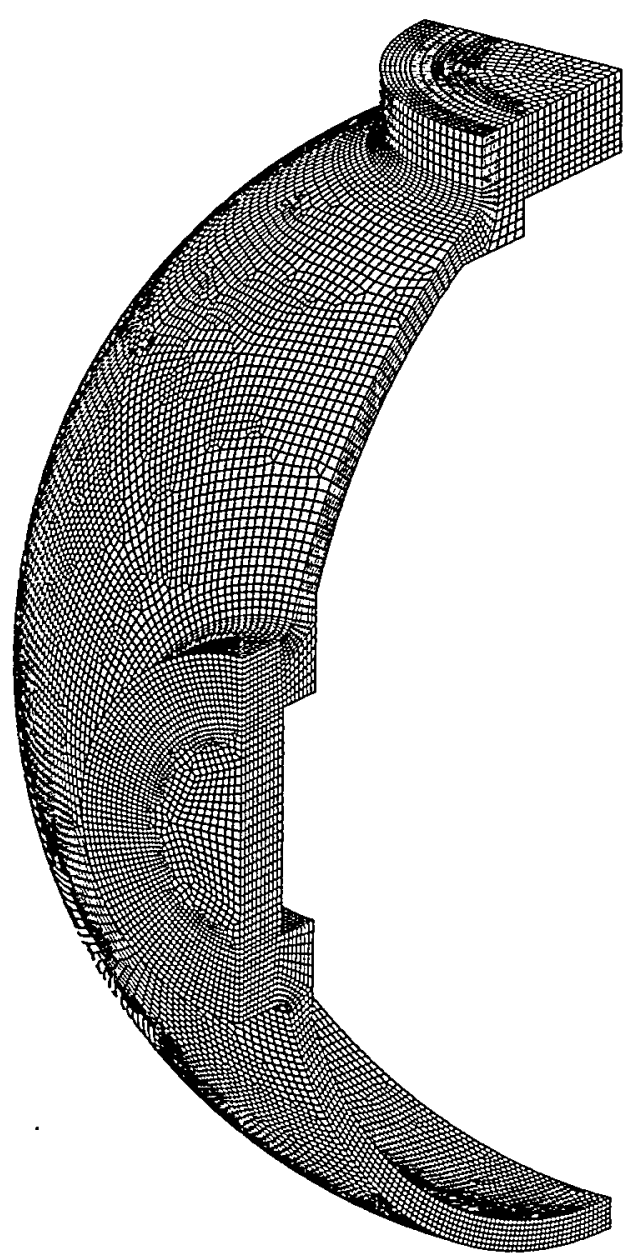

Fig. 7. The mesh used for the simplified-port analyses.

internal pressure in the vessel. Figure 10 shows the quarter-symmetry version of this model. Figure 11 shows a close-up of the bolted connection between the vessel and the top (22-in.) port. This family of meshes is referred to as the "d" series.

The bolts were given a quasi-static preload of $32 \mathrm{ksi}$ (tension) before the transient pressures were applied. This was accomplished by using a temperature-sensitive material model for the bolts and artificially lowering the temperature, thereby causing a contracting thermal strain and the desired tensile preload. The temperature was decreased sufficiently slowly that preload was applied quasistatically. There was very little "ringing" observed after the preload was applied. Figure 12 shows the tensile stress developed in a typical bolt during the preload step.

Special "strain gage elements" were added to the model at the locations of the strain gages used in vessel tests (described below). These elements were simply membrane elements, sharing the nodes of the exterior face of the closest brick for each strain gage location. Using these membrane elements allowed the strain to be calculated at the outer surface of the vessel, rather than at the integration point of the closest brick. 


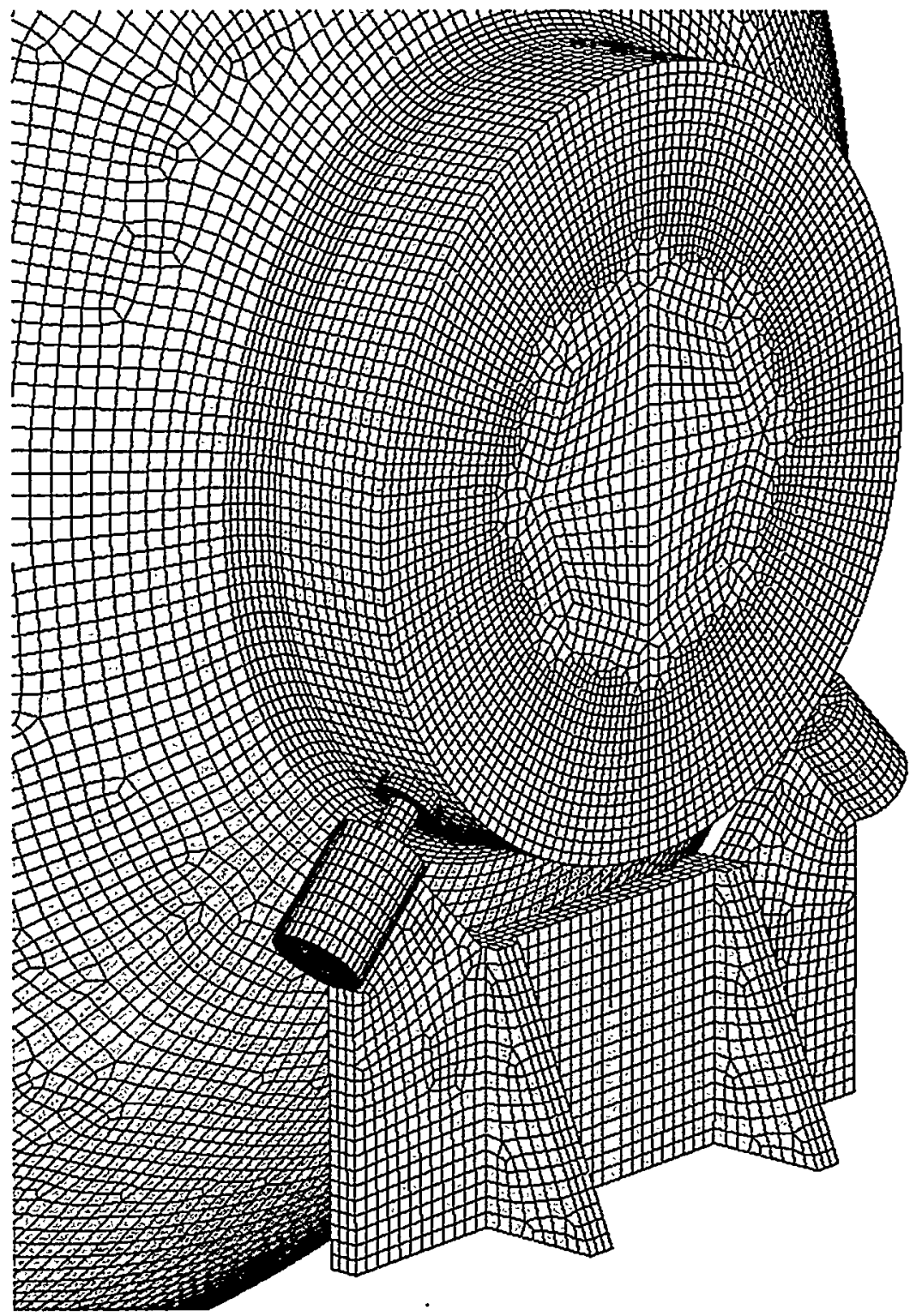

Fig. 8. The model used for runs that included the vessel support stand.

As shown in Fig. 2, the nominal distance from the main mating surface of the door/nozzle interface to the shoulder mating surface was 3.0 in. (for the 22 -in. port), but the tolerances specified will usually result in parts that contact at the shoulder and have a small gap at the main mating surface. This geometric tolerance was seen to have a significant effect on the strains produced in the bolts (described later). For all results described in this report, the dimension for the nozzles was taken as halfway between the minimum and maximum tolerance, or 2.995 in., leaving a gap of 0.005 in. at the main mating surface between each door and nozzle. 


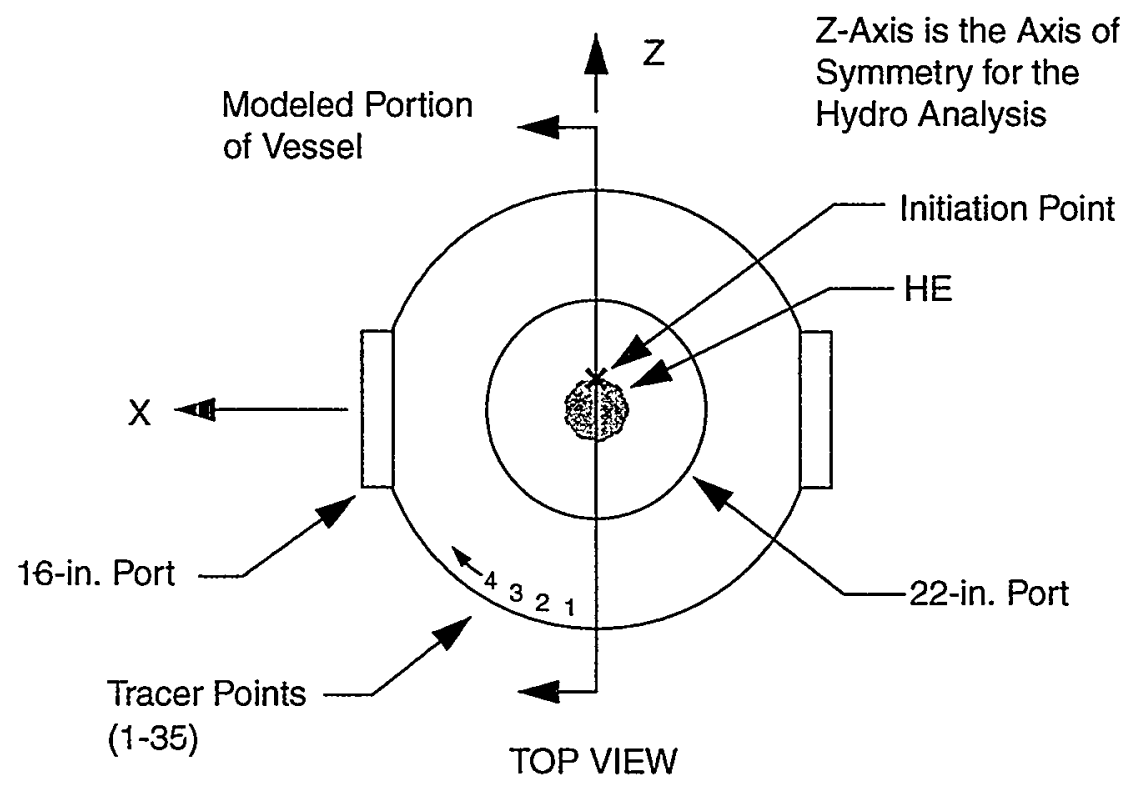

Fig. 9. Schematic diagram for the off-center HE initiation load cases, showing the location of the $\mathrm{HE}$ initiation point relative to the vessel.

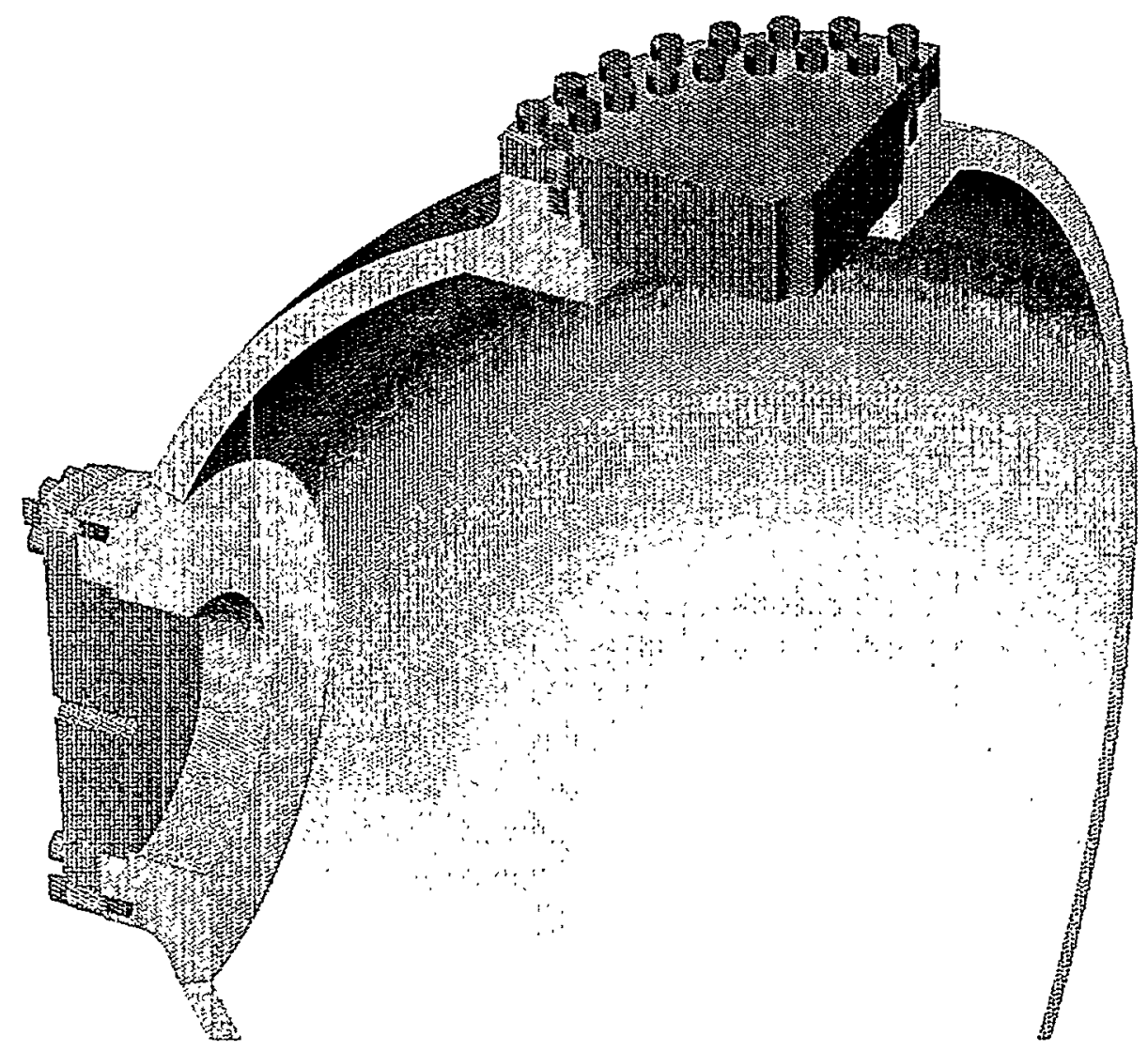

Fig. 10. The high-detail structural model using individually modeled bolts. 


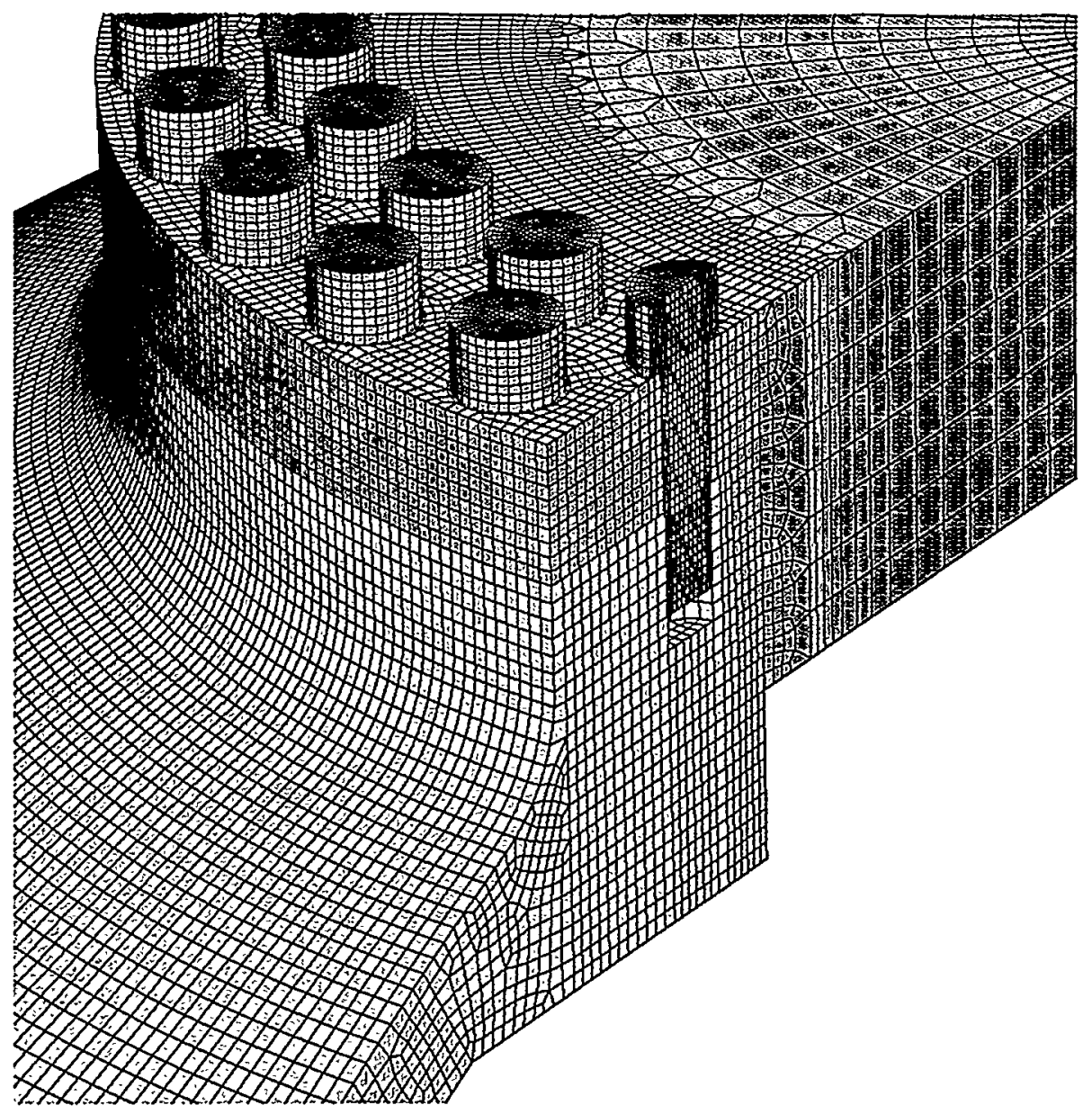

Fig. 11. A close-up of the 22-in. port connection in the detailed-port structural model.

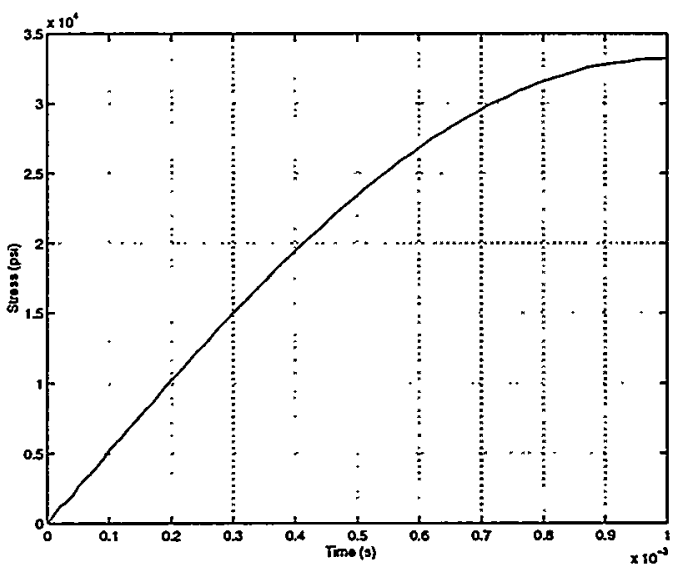

Fig. 12. The tensile preload in the port bolts was applied quasi-statically over a period of $1.0 \mathrm{~ms}$ before the transient pressures were applied. 


\section{MATERIAL MODELS}

\section{a) HE and Air Equations of State}

The JWL equation of state (named for Jones, Wilkins, and Lee [5]) was used to model the gaseous detonation products that produce the impulse on the vessel wall. The form of the JWL equation of state is:

$$
P=A\left[1-\frac{\omega}{R_{1} V}\right] e^{-R_{1} V}+B\left[1-\frac{\omega}{R_{2} V}\right] e^{-R_{2} V}+\frac{\omega E}{V},
$$

where $P$ is the pressure of the detonation products during expansion, $A$ and $B$ are linear coefficients from empirical calibration (units of pressure), $R_{1}, R_{2}$, and $\omega$ are nonlinear coefficients from empirical calibration (unitless), $v=v / v_{0}$ is the ratio of detonation product volume $v$ to initial explosive volume $v_{0}$, and $E$ is the detonation energy per unit volume.

The coefficients used in the JWL equation of state are obtained from physical measurement and detonation experiments that yield initial density, detonation velocity, Gurney energy, detonation pressure, and heat of detonation. The values of the coefficients derived for PBX-9501 are shown in Table 1 below. As mentioned above, the calibration process for the JWL equation of state

Table 1: Equation of State Parameters for PBX-9501

\begin{tabular}{|c|c|}
\hline $\begin{array}{c}\text { JWL } \\
\text { Parameter }\end{array}$ & PBX-9501 \\
\hline \hline $\mathrm{R}_{1}$ & 4.550 \\
\hline $\mathrm{R}_{2}$ & 1.300 \\
\hline$\omega$ & 0.380 \\
\hline $\mathrm{A}(\mathrm{Mbar})$ & 8.524 \\
\hline $\mathrm{B}$ (Mbar) & 0.1802 \\
\hline $\mathrm{E}$ (Mbar) & 0.1020 \\
\hline
\end{tabular}

involves combining experimental measurements with four constraints [6], which yields four unknowns in four equations that must be iteratively solved. One of the constraints applied during this process is that the work done at a chosen truncation volume must be simply correlated with the empirically determined Gurney energy. This expansion ratio cutoff is commonly chosen to be less than or equal to a value of seven (i.e., a product gas expansion less than seven times the original HE volume); therefore, using JWL coefficients determined from a nominal set of cylinder tests leads to error towards the end of the HE principal isentrope (past the truncation volume). This fact is a source of error in the analysis presented here because expansion ratios are larger than the nominal truncation values chosen during the JWL calibration process; however, the end effect on overall vessel response is assumed to be small because the coefficients are chosen so that the work done at complete expansion equals the total chemical energy (another of the four 
constraints mentioned above) and because parametric variations in the arrival time of the detonation products using the structural model indicate a negligible effect. It is recommended that this source of error be further investigated and quantified through additional analysis and experimentation. For the air, a Sesame look-up table was used to determine the pressure-volume dependence of air at both STP (standard temperature and pressure) and LANL conditions. Sesame is a collection of equation-of-state (EOS) data tables that give thermodynamic properties (e.g., pressure and specific energy) as functions of material composition, mass density, and temperature. The EOS tables are constructed by combining theoretical models with experimental data [7].

\section{b) HSLA-100 Steel}

Numerous tests have been conducted on HSLA-100 in both plate and forged forms $[8,9,10]$. The material exhibits a slight amount of softening over the temperature range of interest and also exhibits a slight amount of strain rate dependence. For analysis purposes, these effects were neglected, and a single stress-strain curve was used that was representative of the highest temperature at which the vessel would be used and a quasi-static strain rate. This approach was considered conservative.

A tabular elastic-plastic material model was used to model the HSLA-100 steel. The measured true stress, true strain curve as well as the elastic-plastic model is shown in Fig. 13. The stressstrain curve used was measured at a temperature of $123^{\circ} \mathrm{F}$ and a strain rate of $0.001 / \mathrm{s}$; the test specimen was cut from the surface of the plate, lying in the plane of the plate, and aligned with the rolling direction.

The same material model was used to represent the forged components and the welded regions of the vessel.

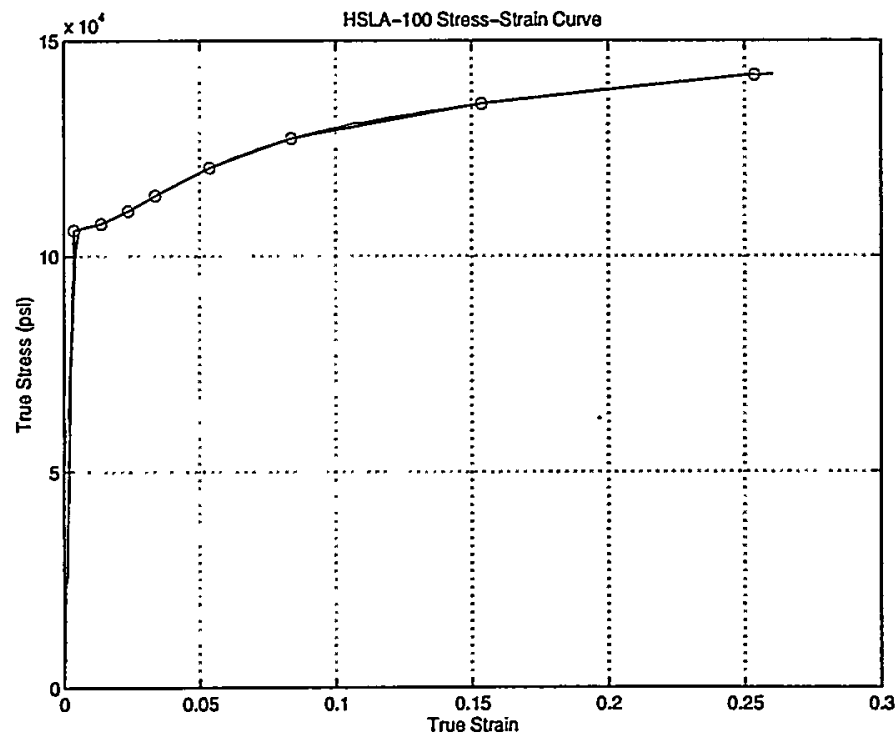

Fig. 13. Stress-strain curve used to represent the HSLA-100 material behavior. 


\section{COUPLING OF HYDROCODE AND STRUCTURAL ANALYSES}

The pressures calculated in the hydrodynamic analyses were used as input to the structural analyses. The handoff of the pressure data involved several important assumptions and checks, which are described below.

A key assumption in the approach is that the hydrodynamic and structural analyses are uncoupled: the pressures calculated by the hydrodynamic analysis drive the structural response, but the structural response of the vessel does not significantly affect the pressures generated within the vessel. This assumption is justified because there is a large density difference between the air and the steel [11]. This coupling can be quantified by considering the equation of motion for a moderately thick walled elastic vessel [12].

\section{a) Assignment of Applied Pressures}

The pressure data generated by the hydrodynamics codes were computed at a discrete number of locations, called tracer points. For the center-detonated load cases, the pressure applied to the vessel was taken to be uniform at all locations on the inner surface of the vessel. The pressuretime history was created by averaging the pressure at all tracer points. For the off-center initiation load case, the pressure distribution on the inner surface of the vessel was not uniform, so that each of the tracer points was assigned to a set of the structural model's element faces. The pressures calculated at each tracer point were assigned to the inner surfaces of the vessel on a nearestneighbor basis. The assignment map is shown in Fig. 14.

The assignment of elements to tracer points was done on a strictly nearest-neighbor basis: no interpolation of pressure between two tracer points was attempted. An interpolation scheme in which an element located between two tracer points is loaded by a linear combination of both tracer-point pressure histories was considered but rejected for the reason that spatial interpolation of time-varying functions destroys the traveling-wave nature of the function.

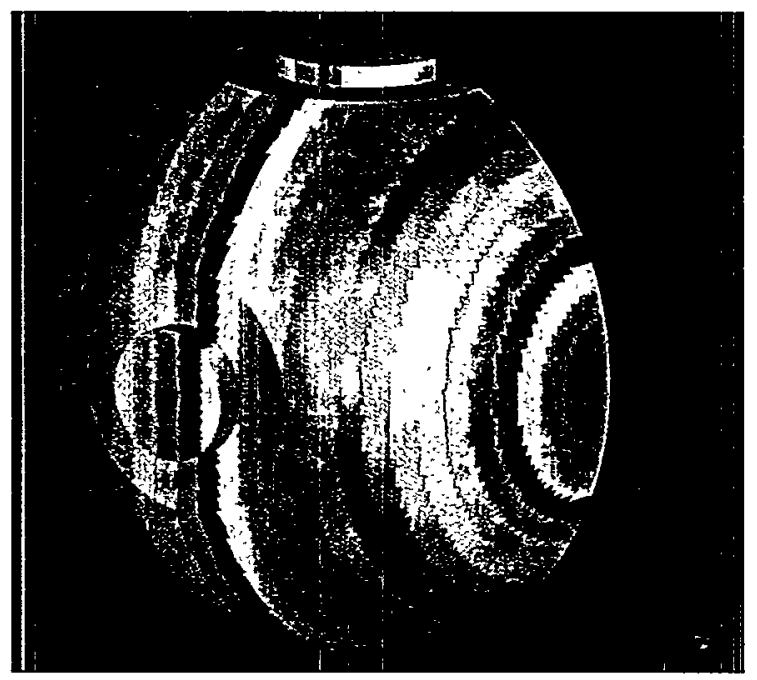

Fig. 14. Assignment of groups of element faces on the inner surface of the vessel to the nearest (axisymmetric) tracer point. Each color corresponds to one tracer point. 


\section{b) Adjustment of Applied Pressures for Zero Net Impulse}

The vessel's support stand was included in one analysis but omitted in subsequent analyses because its effect on the stresses produced in the vessel was negligible. In the cases for which the support stand was omitted, the vessel was free to "float" without any external constraints. Because the blast pressures represent internal forces only, there are no external forces acting on the vessel, and the momentum of the system must remain unchanged by the applied pressures. Thus, the applied pressures must result in zero net impulse on the vessel. However, the net impulse (calculated by a simple program, independent of the structural analysis code) had a small positive value in the direction of the axis of symmetry used in the MESA2D calculations. This error was caused by the fact that a small amount of area at the center of the doors was not modeled, and, in the case of the one point, off-center initiation, the piecewise pressure assignment scheme was not exact. The error was corrected by applying a simple scale factor to the pressure history for the 22-in. door. The scale factor required to make the net impulse exactly equal to zero was 1.0188 . By increasing the pressures on the door (rather than decreasing the pressures on the other side of the vessel), the modification was considered conservative.

\section{RESULTS}

\section{a) Outline of All Analyses}

Table 2 provides an outline of all analyses that were considered. Various important aspects of each of these analyses will be discussed in the subsequent sections.

\section{b) Description of Vessel Response}

The vessel response was qualitatively similar for all of the load cases considered. The vessel initially deforms in a "breathing mode," an almost-uniform radial expansion of the entire vessel and ports. Because of the asymmetry of the vessel's ports (in terms of mass and stiffness), the uniform radial breathing mode degenerates after a couple of cycles into a more complex combination of bending/extensional modes. The stresses caused by the bending action are significantly greater than the stresses caused by the initial breathing response.

The early dominance of the breathing mode, followed after a few vibration cycles by the bending/ extensional modes, was exhibited by all of the models and all of the load cases, including the offcenter HE initiation load cases. However, the vessel response for the off-center initiation load cases was significantly more severe than for the center-initiated load cases. The reason for this difference was believed to be the nonisotropic gas dynamics in the vessel caused by the off-center initiation. This effect is described in more detail in the section, "d) Applied Pressures, Off-Center Initiation."

The stress response on the vessel walls typically exhibited a "beating" effect, in which the amplitude of the bending stress was modulated by a relatively low-frequency harmonic. This effect is evident in Fig. 15, which shows a typical outer surface stress history. The frequencies of the low- 
Table 2: Model Configurations and Load Cases

\begin{tabular}{|c|c|c|}
\hline Mesh $^{1}$ & Loading $^{2}$ & Comments ${ }^{3,4}$ \\
\hline $\mathrm{vi}$ & $\begin{array}{l}\text { 10-lb HE, } \\
\text { MESA2D }\end{array}$ & - run time: 12.5 minutes on $1 \times 64$ processors \\
\hline vi & $\begin{array}{c}\text { 20-lb HE, } \\
\text { CTH }\end{array}$ & - run time: 24 minutes on $1 \times 32$ processors \\
\hline vi & $\begin{array}{c}\text { 40-lb HE, } \\
\text { CTH }\end{array}$ & - run time: 22 minutes on $1 \times 32$ processors \\
\hline vii & $\begin{array}{l}\text { 10-lb HE, } \\
\text { MESA2D }\end{array}$ & $\begin{array}{l}\text { - includes vessel support stand } \\
\text { - used dynamic relaxation to apply static load } \\
\text { - run time: } 8.6 \text { hours on } 1 \times 16 \text { processors }\end{array}$ \\
\hline viii & $\begin{array}{l}\text { 10-lb HE, off- } \\
\text { center initia- } \\
\text { tion, CTH }\end{array}$ & $\begin{array}{l}\text { - one plane of symmetry (one-half of vessel } \\
\text { explicitly modeled) } \\
\text { - run time: } 42 \text { minutes on } 1 \text { x } 32 \text { processors }\end{array}$ \\
\hline viii & $\begin{array}{l}\text { 20-lb HE, off- } \\
\text { center initia- } \\
\text { tion, CTH }\end{array}$ & $\begin{array}{l}\text { - one plane of symmetry (one-half of vessel } \\
\text { explicitly modeled) } \\
\text { - run time: } 42 \text { minutes on } 1 \text { x } 32 \text { processors }\end{array}$ \\
\hline viii & $\begin{array}{l}\text { 40-lb HE, off- } \\
\text { center initia- } \\
\text { tion, CTH }\end{array}$ & $\begin{array}{l}\text { one plane of symmetry (one-half of vessel } \\
\text { explicitly modeled) } \\
\text { run time: } 42 \text { minutes on } 1 \times 32 \text { processors }\end{array}$ \\
\hline $\mathrm{di}$ & $\begin{array}{l}\text { 10-lb HE, } \\
\text { MESA2D }\end{array}$ & - run time: 5.8 hours on $4 \times 126$ processors \\
\hline $\mathrm{di}$ & $\begin{array}{c}\text { 20-lb HE, } \\
\text { CTH }\end{array}$ & - run time: 5.8 hours on $4 \times 126$ processors \\
\hline
\end{tabular}

1) All " $v$ " series models represented the ports in a simplified manner in which the doors were assumed to be "tied" to their nozzles. All "d" series models represented the ports in a more detailed manner, explicitly modeling the bolts and using appropriate contact conditions between all mating surfaces.

2) Except where noted otherwise, all loadings were based on a solid sphere of PBX-9501, detonated at the center of the sphere.

3) Except where noted otherwise, all models took advantage of two planes of symmetry, thereby explicitly modeling $1 / 4$ of the vessel.

4) All run times are for the structural analysis code only (not the hydrocode).

frequency "beating envelope" and of the high-frequency bending mode taken from this figure are around $31 \mathrm{~Hz}$ and $1,375 \mathrm{~Hz}$, respectively.

When two signals with closely spaced frequencies are combined, the combination can be viewed as a modulation of two different frequencies. This "beat phenomenon" is expressed by the trigonometric identity:

$$
\cos \omega_{1} t+\cos \omega_{2} t=2 \cos \left(\frac{\omega_{1}-\omega_{2}}{2}\right) t \cos \left(\frac{\omega_{1}+\omega_{2}}{2}\right) t
$$




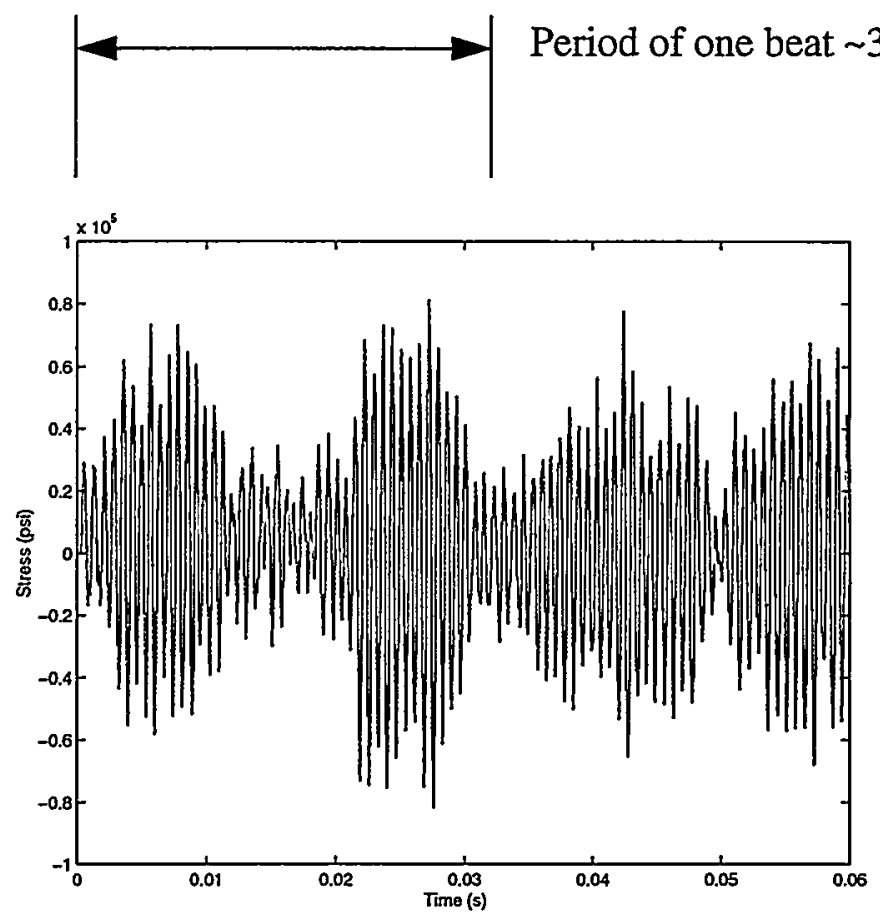

Fig. 15. The meridional component of stress on the outer surface of the vessel at the south pole. Note the beating phenomenon at a frequency of about $31 \mathrm{~Hz}$.

Using this relation, the modulator and modulated frequencies of $31 \mathrm{~Hz}$ and $1,375 \mathrm{~Hz}$ correspond to natural modes at $1,344 \mathrm{~Hz}$ and $1,406 \mathrm{~Hz}$.

By observing the deformed shape of the vessel during its dynamic response (see Fig. 16), it was apparent that the $i=8$ bending/extensional mode (where $i$ is the meridional wave number) was highly excited in conjunction with the $\mathrm{j}=2,4$, and 8 circumferential wave numbers. According to a study [13] of the natural frequencies of this vessel, the fundamental breathing mode $(i=0, j=0)$ has a frequency of $1,421 \mathrm{~Hz}$. The $\mathrm{i}=8$ family of bending/extensional modes has frequencies between 1,260 and 1,390 Hz. The frequencies of these natural modes are in reasonable agreement with the corresponding $1,406 \mathrm{~Hz}$ and $1,344 \mathrm{~Hz}$ modes evident in the analytic vessel response. This comparison is only approximate because other natural modes also participate in the vessel response.

For the "d" series models, it was observed that the bolt preload caused the initial gap at the main mating surface of each of the ports to partially close (this initial gap of 0.005 in. was described in Section IV-d). The outer edge of the door actually came into contact with the outer edge of the nozzle, but the inner edges (near O-ring A) did not actually contact each other.

\section{c) Applied Pressures, Center Initiation}

The pressure-time histories used for the 10-, 20-, and 40-lb HE load cases (center initiation) are shown in Fig. 17. The pressures were calculated for a duration of approximately $7.0 \mathrm{~ms}$, sufficient 


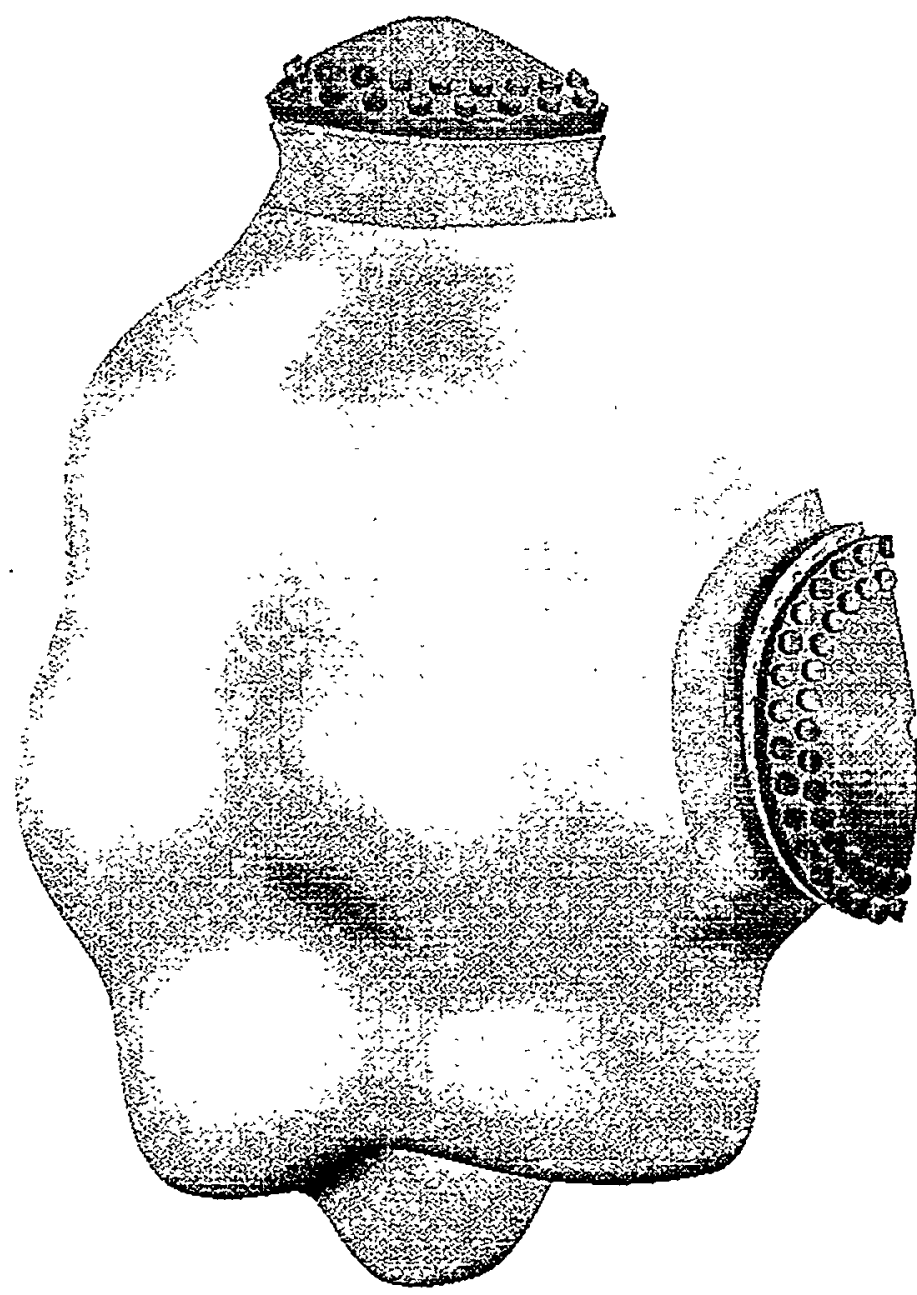

Fig. 16. The deformed shape of the vessel at an arbitrary time, with the displacements exaggerated.

to cover the initial blast loading and several subsequent reverberations inside of the vessel. After the $7.0 \mathrm{~ms}$ of computed pressure, the pressure inside the vessel was taken as constant at the residual pressure. For these center-initiation load cases, the pressure applied to the inner surface of the vessel was taken as an average of the pressures calculated at the tracer point locations near the vessel walls.

The gas products from the HE combustion for all center-initiated load cases exhibited an isotropic oscillatory behavior, where the gas repeatedly "pulsed" in a radially inward/outward periodic motion at a frequency of approximately $1.0 \mathrm{~ms}$.

It was observed that tracer points near the axis of symmetry of the hydro model had significantly greater peak pressures than all other tracer points. This was true even for center-initiated simulations, in which the spherical symmetry of the problem would rule out any "shock focusing" or other geometric cause. Furthermore, hydrocodes other than CTH and models other than the ones used in this report have exhibited this effect. The cause is not known, but it is believed to be 

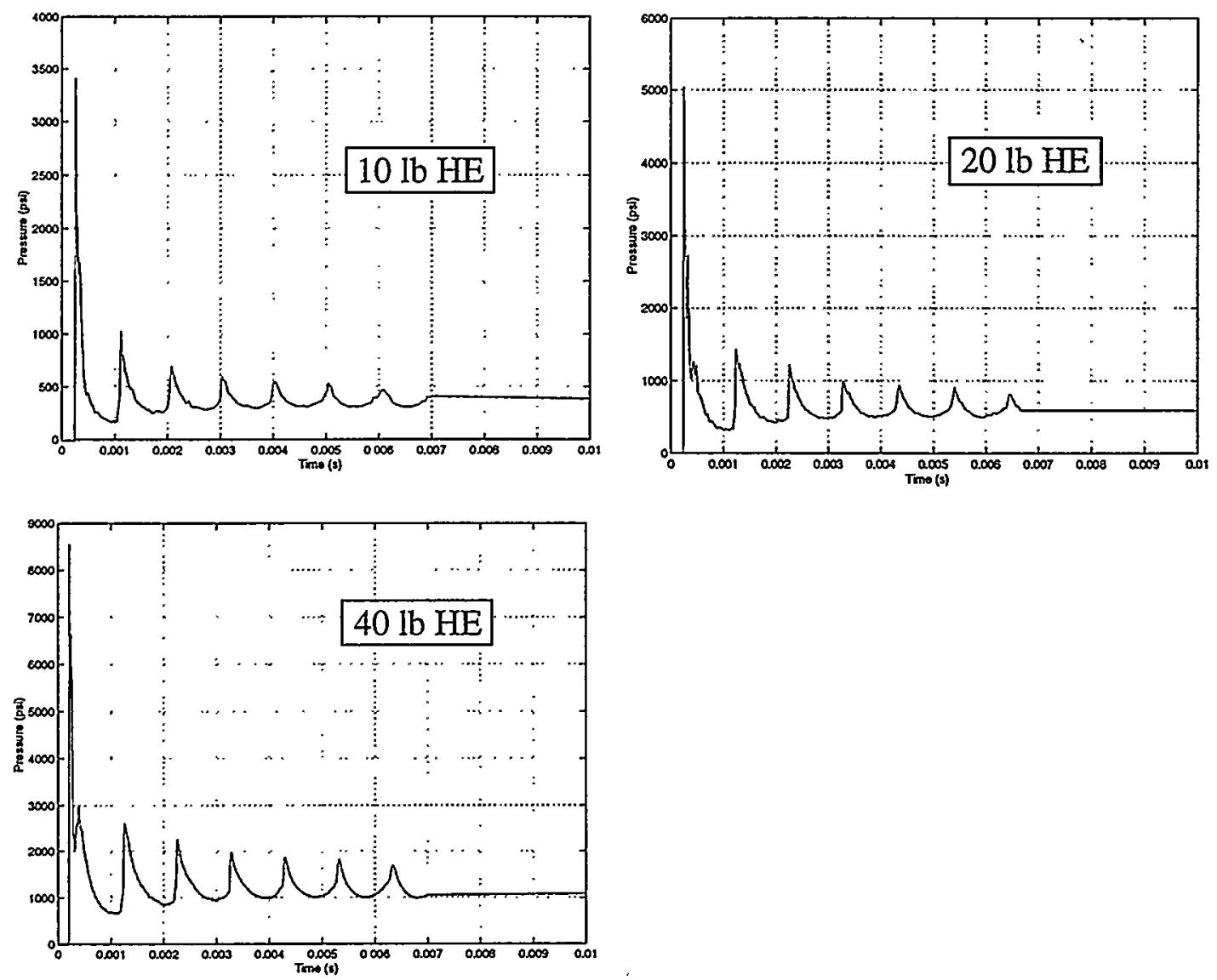

Fig. 17. Pressure-time history for the center-detonated, 10-, 20-, and 40-lb HE load cases.

nonphysical. It was noted that the unit impulse for tracer points near the axis of symmetry was not significantly different than for tracer points far away from the axis of symmetry.

\section{d) Applied Pressures, Off-Center Initiation}

Thirty-five pressure-time histories were generated for the one-point, off-center initiation load cases. The numbering scheme of the "tracer points" (the points at which the pressure was calculated) is shown in Fig. 9. Eight of these 35 pressure-time histories are shown in Fig. 18 for all three of the load cases. The eight pressure-time histories correspond to tracer points $1,5,10,15$, 20, 25, 30, and 35 (see Fig. 9 for the tracer-point numbering scheme).

The gas products from the HE combustion for all off-center-initiated load cases exhibited a nonisotropic oscillatory behavior. The gas response (pressure, density, and velocity) was a periodic "pulsing" with a strong left-to-right (on the Z-axis) component. The frequency of the left-toright pulsing was approximately $2.2 \mathrm{~ms}$. Figure 19 shows a schematic diagram of the two load cases that help illustrate this situation. The nonisotropic (i.e., nonradially symmetric) aspect of the pressure response is due to the fact that the detonation products generated behind the plane 

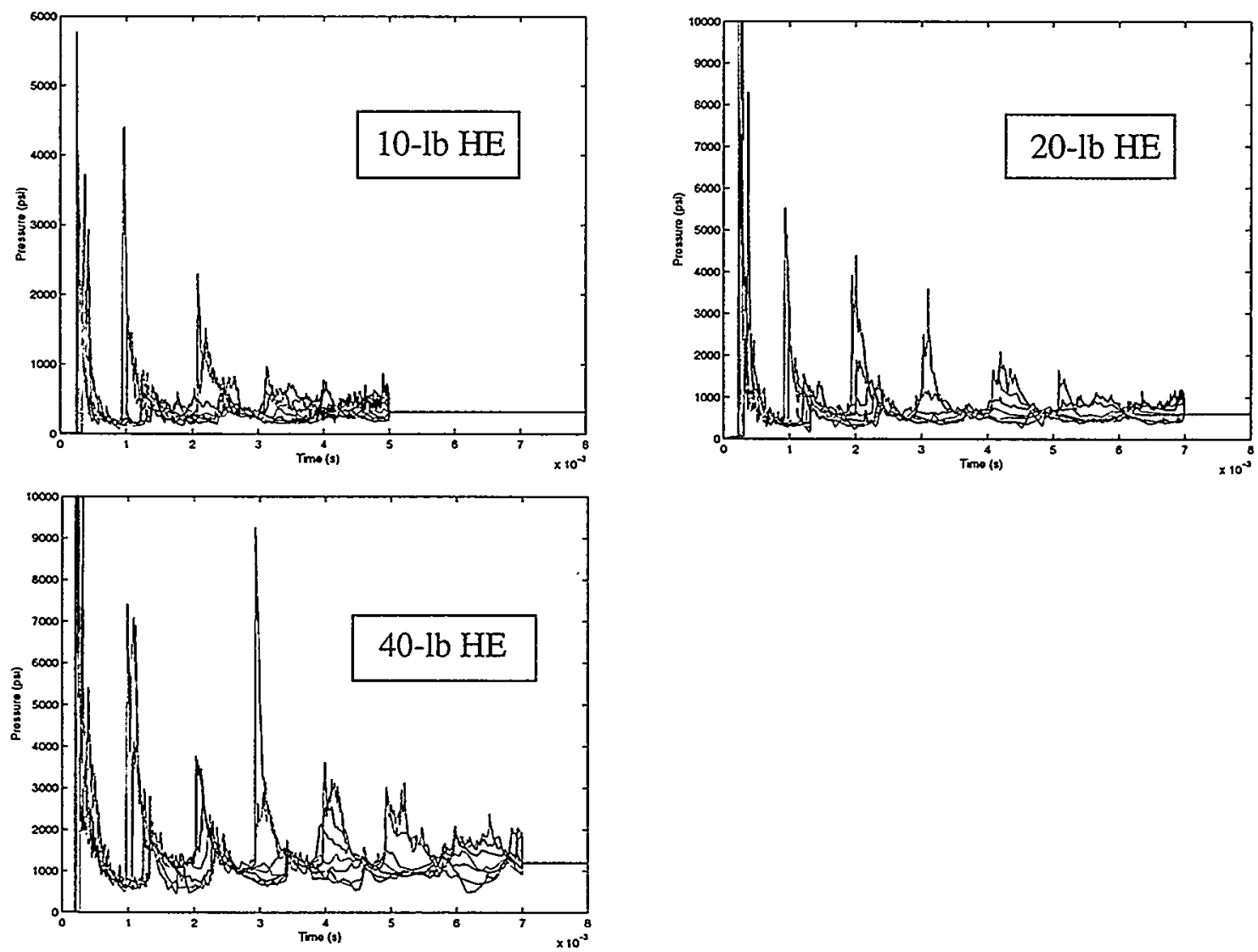

Fig. 18. Pressure-time histories for selected locations for the off-center HE initiation load cases.

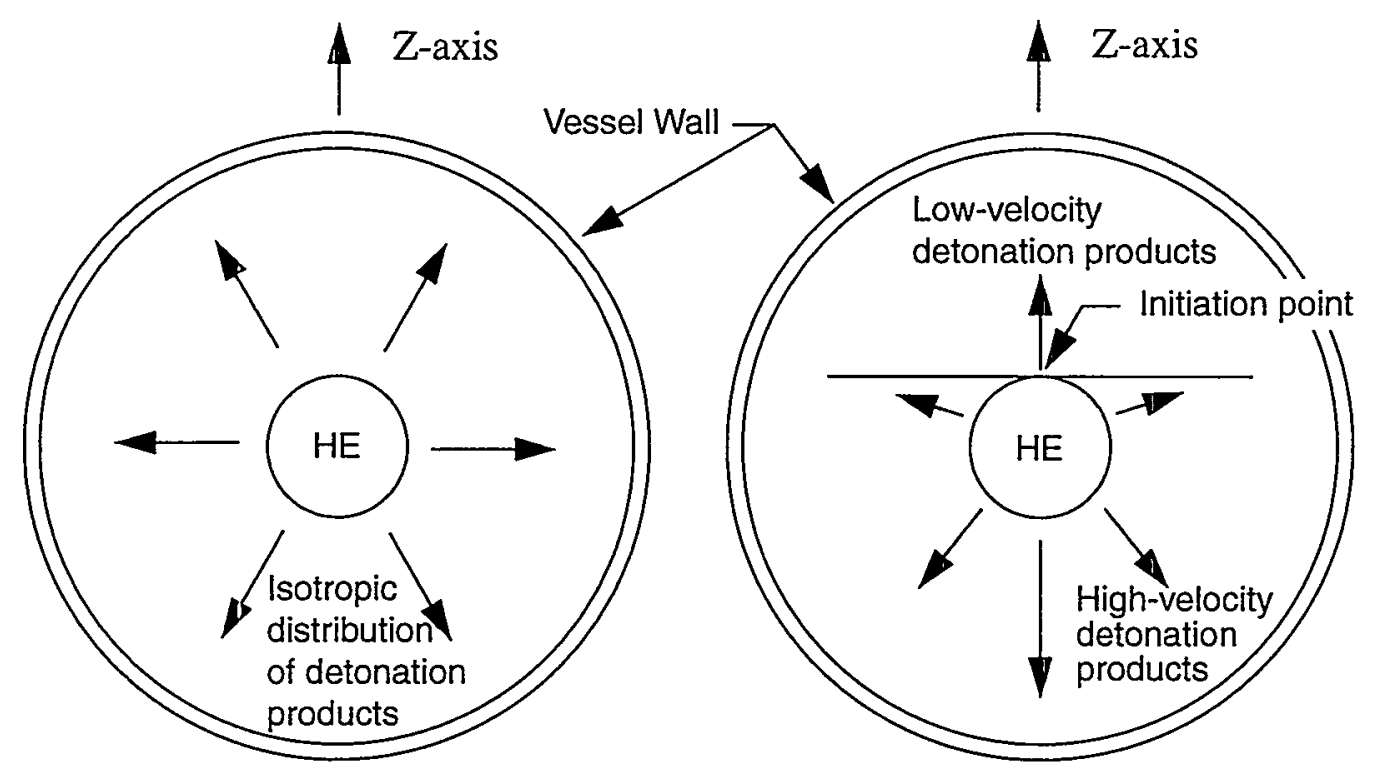

Fig. 19. Schematic diagrams illustrating the initial expansion of the detonation products inside the vessel for the center-initiated (left) and off-center-initiated (right) load cases. 
through the initiation point and normal to the axis of symmetry travel at a slower velocity than the detonation products generated in front of the plane.

Figure 20 shows the pressure-time history at points 1 and 35 (the two points closest to the axis of symmetry) for the $20-\mathrm{lb} \mathrm{HE}$ load case. Note that the initial, large pressure spike arrives at point \#1 about $200 \mu \mathrm{s}$ before it arrives at point \#35, even though point \#35 is closer to the initiation point than point \#1. The back-and-forth pulsing is also exhibited in this figure by the out-of-phase pressure peaks at approximately a 2.2 -ms period.

The integrated unit-impulse for the off-center-initiated load cases was almost identical to that for the center-detonated load cases.

\section{e) Comparison of LS-DYNA and PARADYN Results}

An important objective of the structural modeling effort was to directly compare the results the analysis code, PARADYN, with another analysis code, LS-DYNA, which has been used extensively in previous confinement vessel analyses. The comparison was conducted by running the same simulation (i.e., identical mesh, material models, applied loading, etc.) with both codes, and comparing a few responses (displacement and stress histories) at corresponding points. The " $\mathrm{v}$ " series of meshes was used for these comparisons.

The vessel responses that were compared consisted of two displacement histories and one stress history, as described in Table 3. In all cases, the results of the two codes were essentially identical: when plotted on the same graph, the two curves could not be distinguished.

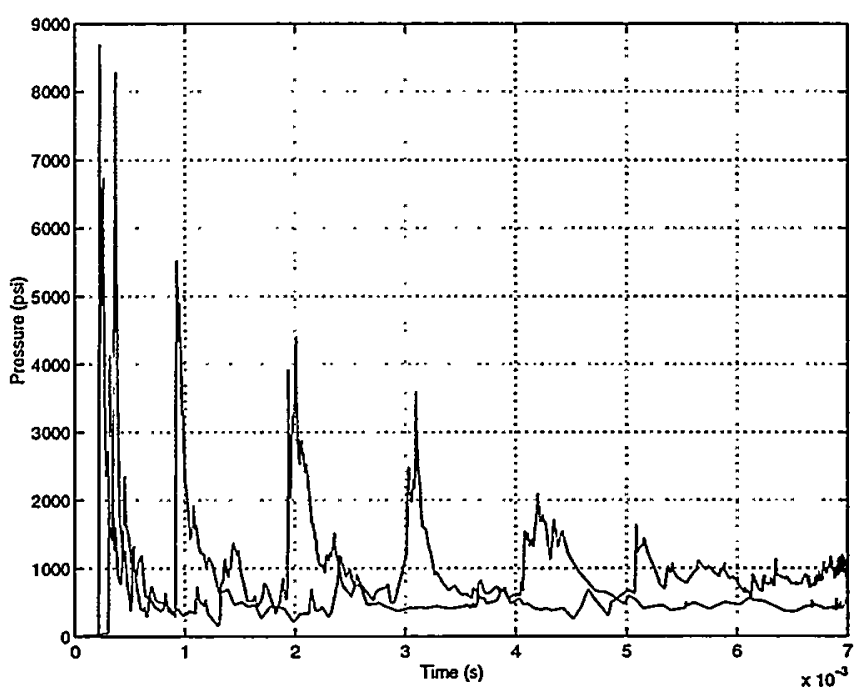

Fig. 20. The pressure-time history for points \#1 and \#35 (the two points closest to the axis of symmetry) for the $20-\mathrm{lb}$, off-center-initiated load case. The blue line is point \#1; the green line is point \#35. 
Table 3: Comparison of LS-DYNA and PARADYN Results

\begin{tabular}{|c|c|c|}
\hline Location & Result & Agreement \\
\hline \hline $\begin{array}{c}\text { Center of 22-in. door, outside surface } \\
\text { (+Y axis) }\end{array}$ & $\begin{array}{c}\text { Y-direction } \\
\text { displacement history } \\
\text { (+X axis) }\end{array}$ & Excellent* \\
\hline $\begin{array}{c}\text { Center of 16-in. door, outside surface } \\
\text { displacement history } \\
\text { (+X axis) }\end{array}$ & $\begin{array}{c}\text { Excellent* } \\
\text { (isplacement history }\end{array}$ & Excellent* \\
\hline "South pole" of vessel (-Y axis), inner surface & $\begin{array}{c}\text { effective stress } \\
\text { history }\end{array}$ & Excellent* \\
\hline "South pole" of vessel (-Y axis), outer surface & $\begin{array}{c}\text { effective stress } \\
\text { history }\end{array}$ & Excellent* \\
\hline \multicolumn{2}{|c|}{ * results were essentially identical over the entire duration of the analysis (20 ms). } \\
\multicolumn{2}{|r}{} \\
\hline
\end{tabular}

It was concluded from these results that the analysis code PARADYN gives identical results to the code LS-DYNA in calculations of the structural response of pressure-loaded vessels and was thus "qualified" to be used for subsequent analyses.

\section{f) Peak Stresses in Vessel}

Table 4 summarizes the peak stresses and strains in the vessel for each of the vi-series and viiiseries load cases. The largest stresses for all center-initiation load cases were induced in the vessel wall near the south pole (bottom) of the vessel, on the inner surface of the vessel, on the XYplane. The center-initiated 40-lb HE load case and the off-center-initiated 20- and 40-lb HE load cases caused plastic yielding in the vessel material.

Table 4: Peak Stresses and Plastic Strains in Vessel

\begin{tabular}{|c|c|c|l|}
\hline Loading & $\begin{array}{c}\text { Peak } \\
\text { Effective } \\
\text { Stress (ksi) }\end{array}$ & $\begin{array}{c}\text { Peak } \\
\text { Equivalent } \\
\text { Plastic Strain }\end{array}$ & $\begin{array}{c}\text { Location of Result } \\
\text { (Clock-referenced positions are relative to a viewer } \\
\text { looking at the vessel from a point on the }+\mathrm{X} \text { axis.) }\end{array}$ \\
\hline \hline $\begin{array}{c}\text { 10-lb HE } \\
\begin{array}{c}\text { center initia- } \\
\text { tion }\end{array}\end{array}$ & 64 & 0 & $\begin{array}{l}\text { (Location of greatest stress): Inner surface of the vessel at a } \\
\text { point on the XY plane between the 16-in. port and the ves- } \\
\text { sel's south pole (brick 61,400) } \\
\text { South pole, outer surface (brick 66,205) }\end{array}$ \\
\hline $\begin{array}{c}\text { 20-lb HE } \\
\text { center initia- } \\
\text { tion }\end{array}$ & 72 & 0 & (Location of greatest stress): Identical to case 1 \\
\hline
\end{tabular}


Table 4: Peak Stresses and Plastic Strains in Vessel (Continued)

\begin{tabular}{|c|c|c|c|}
\hline Loading & $\begin{array}{c}\text { Peak } \\
\text { Effective } \\
\text { Stress (ksi) }\end{array}$ & $\begin{array}{l}\text { Peak } \\
\text { Equivalent } \\
\text { Plastic Strain }\end{array}$ & $\begin{array}{l}\text { Location of Result } \\
\text { (Clock-referenced positions are relative to a viewer } \\
\text { looking at the vessel from a point on the }+X \text { axis.) }\end{array}$ \\
\hline $\begin{array}{l}40 \text {-lb HE } \\
\text { center initia- } \\
\quad \text { tion }\end{array}$ & $\begin{array}{l}106 \\
106\end{array}$ & $\begin{array}{r}8.9 \mathrm{e}-04 \\
4.0 \mathrm{e}-4\end{array}$ & $\begin{array}{l}\text { (Location of greatest plastic strain): Identical to case } 1 \\
\text { South pole, outer surface (brick } 66,205 \text { ) }\end{array}$ \\
\hline $\begin{array}{l}10-\mathrm{lb} \mathrm{HE} \\
\text { off-center ini- } \\
\text { tiation }\end{array}$ & $\begin{array}{l}75 \\
70 \\
64\end{array}$ & $\begin{array}{l}0 \\
0\end{array}$ & $\begin{array}{l}\text { (Location of greatest stress): Inner surface of the vessel at a } \\
\text { point on the YZ plane at approximately the 5:00 position } \\
\text { (brick 156,111) } \\
\text { Blend between the vessel wall and the 16-in. nozzle, at } \\
\text { approximately the } 4: 00 \text { position (brick } 166,179 \text { ) } \\
\text { Blend between the vessel wall and the } 16 \text {-in. nozzle, at } \\
\text { approximately the } 6: 00 \text { position (brick } 66,974 \text { ) } \\
\text { South pole outer surface (brick } 66,205 \text { ) }\end{array}$ \\
\hline $\begin{array}{l}\text { 20-lb HE } \\
\text { off-center ini- } \\
\quad \text { tiation }\end{array}$ & $\begin{array}{l}106 \\
106 \\
99\end{array}$ & $\begin{array}{l}1.7 \mathrm{e}-03 \\
2.5 \mathrm{e}-04 \\
2.7 \mathrm{e}-04 \\
0\end{array}$ & $\begin{array}{l}\text { (Location of greatest plastic strain): Inner surface of the ves- } \\
\text { sel at a point on the YZ plane at approximately the 5:00 } \\
\text { position (brick 156,087) } \\
\text { Blend between the vessel wall and the } 16 \text {-in. nozzle, at } \\
\text { approximately the } 4: 00 \text { position (brick } 166,083 \text { ) } \\
\text { Blend between the vessel wall and the } 16 \text {-in. nozzle, at } \\
\text { approximately the } 8: 00 \text { positions (brick } 66,637 \text { ) } \\
\text { South pole outer surface (brick } 66,205 \text { ) }\end{array}$ \\
\hline $\begin{array}{l}\text { 40-lb HE } \\
\text { off-center ini- } \\
\text { tiation }\end{array}$ & $\begin{array}{l}107 \\
107 \\
106 \\
106\end{array}$ & $\begin{array}{l}1.6 \mathrm{e}-02 \\
1.6 \mathrm{e}-02 \\
2.5 \mathrm{e}-02 \\
5.8 \mathrm{e}-03\end{array}$ & $\begin{array}{l}\text { (Location of greatest plastic strain): Blend between the ves- } \\
\text { sel wall and the 16-in. nozzle, at approximately the 4:00 } \\
\text { position (brick 157,749). } \\
\text { Blend between the vessel wall and the 16-in. nozzle, at } \\
\text { approximately the } 8: 00 \text { position (brick } 66,446 \text { ). } \\
\text { Outer surface between the 16-in. port and the south pole } \\
\text { (XY plane, brick } 152,186 \text { ) } \\
\text { Inner surface of vessel wall, on YZ plane at approximately } \\
\text { the } 4: 00 \text { position (brick } 121779 \text { ) } \\
\text { South pole outer surface (brick } 66,205 \text { ) }\end{array}$ \\
\hline
\end{tabular}

Figure 21 shows the equivalent stresses at a particular instant for the off-center-initiated, 10-lb HE load case. Figure 22 shows the equivalent plastic strains for the off-center-initiated, 20-lb HE load case, and Fig. 23 shows the equivalent plastic strains for the off-center-initiated, 40-lb HE load case. The plastic strains produced for all load cases were small in magnitude and localized in extent. Furthermore, the plastic strains existed near the surface only: no plastic strain was 
developed near the middle of the vessel wall. This is representative of a bending action, as opposed to a membrane ("stretching") action.



Fig. 21. Effective stresses at a particular instant of time for the off-center-initiation, 10-lb HE load case.

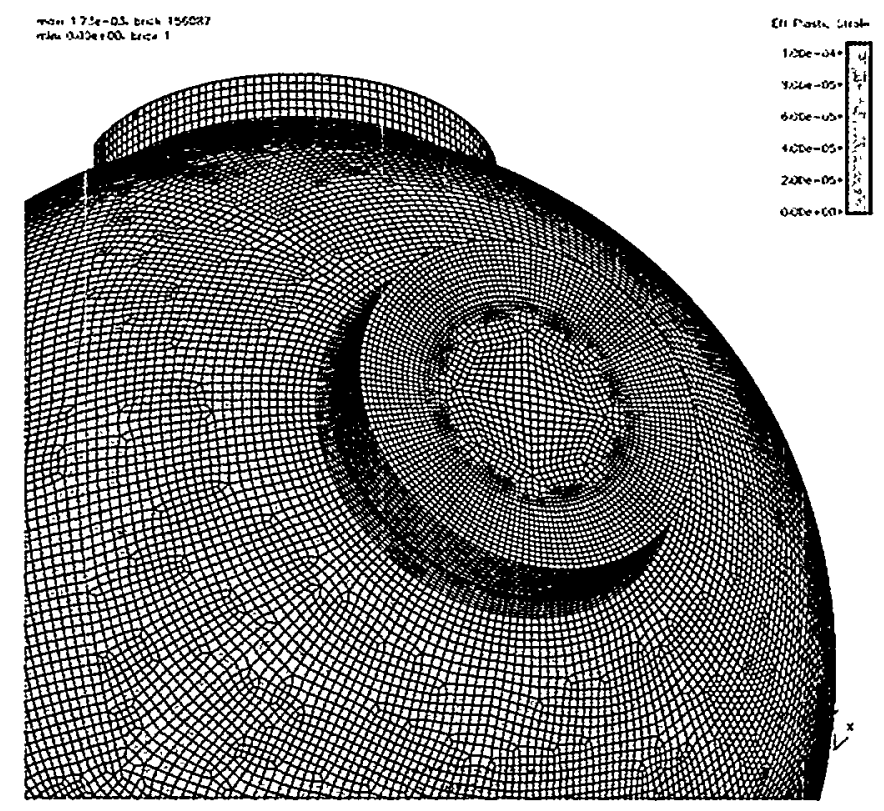

Fig. 22. Equivalent plastic strain produced by the 20-1b HE load case. These are the 4:00 and 8:00 positions on the blend between the 16-in. nozzle and the vessel. 


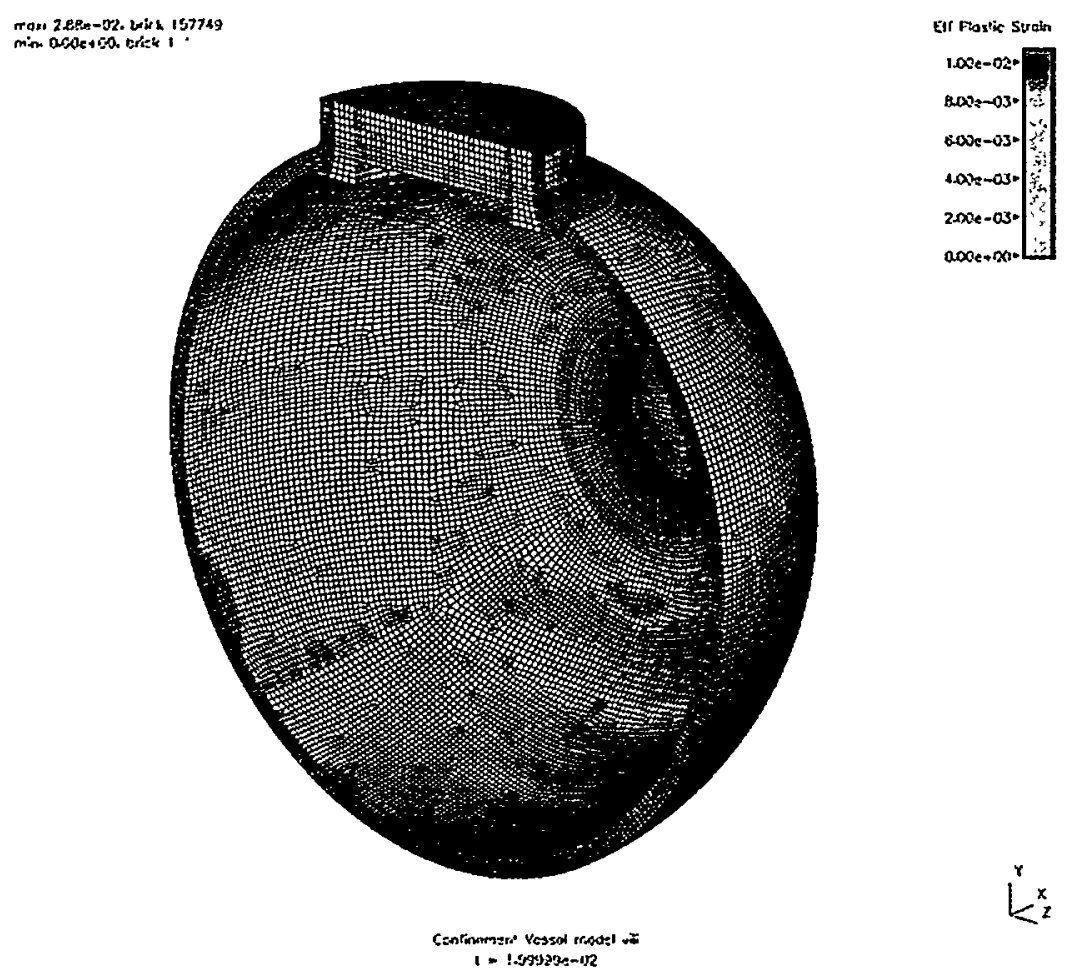

Fig. 23. Equivalent plastic strain produced by the 40-lb HE load case.

\section{g) Effect of Vessel Support Stand}

The effect of the vessel support stand and the static loading caused by the vessel's weight was investigated using the model shown in Fig. 8.

The static weight of the vessel was applied using a technique called dynamic relaxation. This technique allowed the static response to be calculated by an explicit analysis code, which would otherwise be limited to dynamic analyses. When the dynamic relaxation step was completed the weight of the vessel was reacted by the support stand and the system was in static equilibrium. Then, the transient pressures were applied as they were for all load cases that neglected the support stand.

The displacements at various points on the vessel exhibited a constant offset (when compared to the no-support-stand configuration) caused by the static "sag" of the vessel and support stand. The difference in stresses in the vessel was negligible in all locations except for the direct vicinity of the contact with the support stand. The largest static stress in the vessel was 1,370 psi, directly under the point of contact with the support stand. The transient stresses were essentially identical to those for the load cases that omitted the support stand. The largest static stresses in the support stand were around 5,000 psi, in the cylindrical bolt component. The largest peak transient stresses 
in the support stand were in the range of 20 to $30 \mathrm{ksi}$. The static stresses developed in the vessel and support stand are shown in Fig. 24.
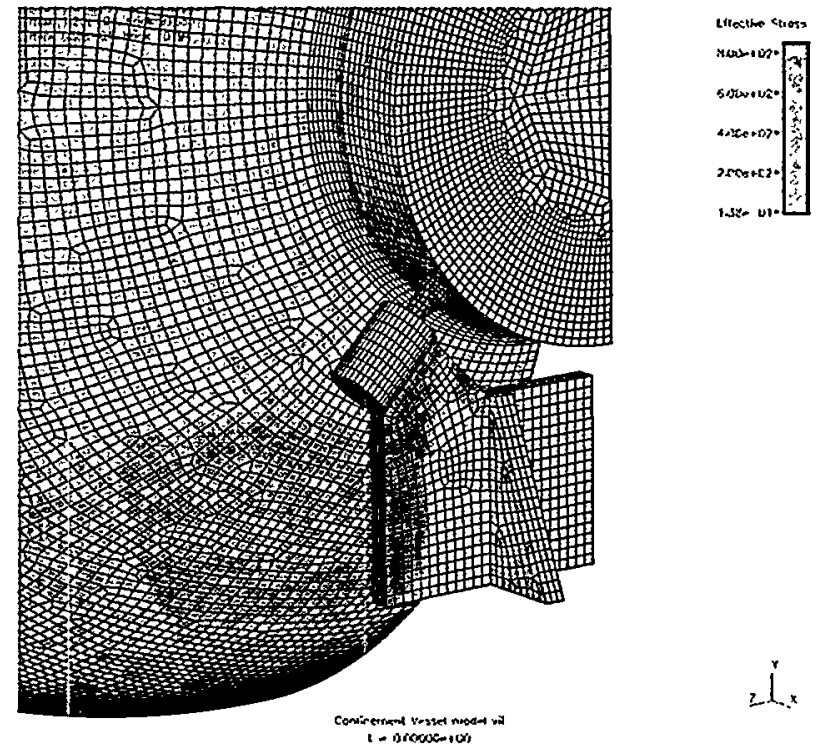

$2 i$

Fig. 24. The static stresses developed in the vessel and support stand.

\section{h) Slip and Gap at O-Ring Seals}

It was desired to estimate the dynamically varying gap across which each of the four O-ring seals in each port must maintain a seal. This gap varies during the response of the vessel because the doors and nozzles were deforming elastically and also because the bolted connections between the doors and nozzles did not clamp the mating parts together perfectly (remaining closed and slip free), but rather allowed some relative motion between the mating parts.

The "d" series models did not explicitly include the O-rings and grooves at each port. However, an estimate of the dynamically varying gap across the seating surfaces of each O-ring was made by subtracting the displacements at each of the four O-ring locations on each nozzle from the corresponding displacements on each door.

The relative motion between the doors and their nozzles at each O-ring location can be resolved into two components: "slip," the relative motion in the plane of the mating surfaces, and "gap," the relative motion normal to the plane of the mating surfaces. The slip and gap were tracked at numerous locations around the circumference of each port. The slip between the nozzle and door of the 22-in. port, measured on the XY plane, is shown in Fig. 25. The gaps at the worst-case locations on the 22-in. port are shown in Fig. 26. It was observed that the peak O-ring gaps were larger at the 22 -in. port than at the 16 -in. port. 


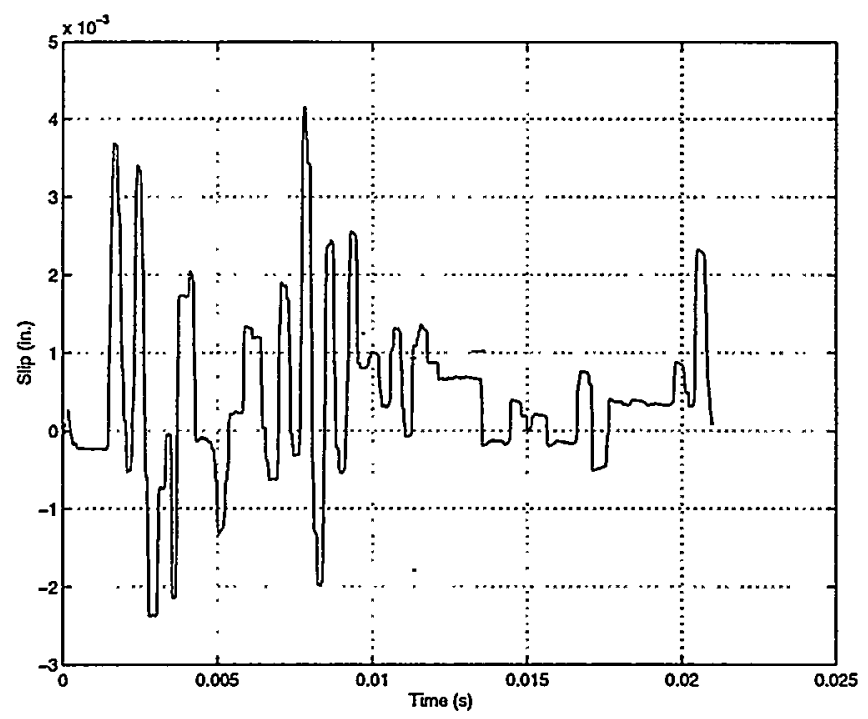

Fig. 25. The slip between the 22-in. door and nozzle, measured at the outer edge of the mating surface on the XY-plane, 10-lb HE load case.

\section{i) Bolt Loading}

The fact that the doors were able to slip relative to their nozzles caused a bending action in the bolts. A picture illustrating this effect is shown in Fig. 27, with the deformations greatly exaggerated to make the slip and gap between the 22-in. door and nozzle obvious and to illustrate the bending and stretching of the bolts.

The axial stress at a point on the center line of the bolt at the midshank location was taken as a reasonable measure of the bolt loading. Note that this measure essentially ignores the bending stresses induced in the bolt. This stress is plotted for bolt \#1 in Fig. 28 (bolt \#1 lies on the inner bolt circle at the XY-cutting plane of the 22-in. port).

\section{COMPARISONS TO EXPERIMENTAL TESTS}

A series of four vessel tests were performed to verify the performance of the confinement vessels. These tests also served as a benchmark for the analytical estimates of the vessel response. These tests are designated $3173,3174,3175$, and 3176 , and are fully documented in [14]. The data recorded in the tests included 8 pressure transducers, 14 strain gages, and 6 instrumented bolts capable of measuring the axial strain during the dynamic response of the vessel. Table 5 gives a brief summary of each test. In all tests, the HE was a solid spherical mass of PBX-9501, detonated at its center.

Figure 29 shows a comparison between predicted unit impulse and measured unit impulse for shots 3173,3174 , and 3175 . This figure indicates that both MESA2D and CTH provide a reasonable estimate of the experimentally determined impulses. 

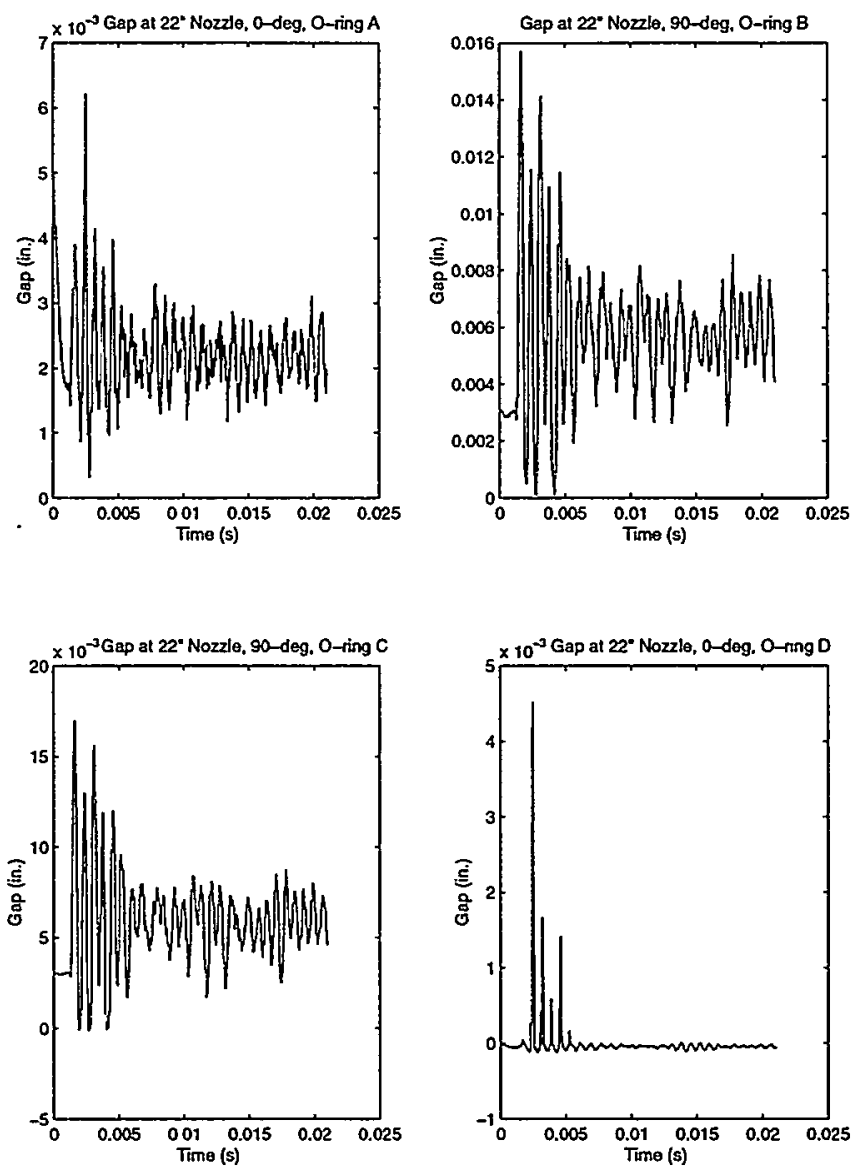

Fig. 26. The dynamic gap between the 22-in. door and nozzle, measured at O-ring locations A, B, C, and D (20-lb HE load case).

Table 5: Summary of Vessel Test Shots

\begin{tabular}{|c|c|c|}
\hline $\begin{array}{c}\text { Test } \\
\text { Designation }\end{array}$ & $\begin{array}{c}\text { Mass of HE } \\
\text { (lb) }\end{array}$ & Comments \\
\hline \hline 3173 & 10 & Baffle plates on 16" ports \\
\hline 3174 & 20 & Baffle plates on 16" ports \\
\hline 3175 & 20 & No baffle plates \\
\hline 3176 & 20 & Vessel filled with blast mitigation material \\
\hline
\end{tabular}

Comparisons of the predicted and measured strains for two of the strain gages are shown in Fig. 30. These strains were calculated using the d-series model. The analytical estimates typically compare reasonably well in terms of peak values and dominant frequency content of the measured strains, especially in the first several milliseconds of the vessel response. The experimental results typically exhibit a more rapid attenuation with time than the analytical results; this was attributed to material damping, which was not accounted for in the models. 




Fig. 27. The deformation of the bolts in the 22-in. nozzle, showing the slip and lift off of the door relative to the nozzle and the stretching and bending that are induced in the bolts. These deformations are exaggerated by a factor of 100 .

The axial strain in six of the bolts connecting a 16-in. door to its nozzle was measured using instrumented bolts. These bolts employed a strain gauge transducer in the shank of the bolt, and were capable of measuring the dynamically varying strain during the vessel response. The strain measured by these bolts was compared to the axial strain at the midshank, center-line position of the corresponding bolts in the d-series models. Fig. 31 shows the comparison for two bolts in the inner bolt circle. It was observed that the bolts on the inner bolt circle were more highly loaded than bolts on the outer bolt circle.

\section{ANALYSIS OF MODELING ERRORS}

There are numerous aspects of the modeling of the confinement vessel itself and of the loading applied to it that were known to be approximate or uncertain. It is instructive to identify them and, to the extent possible, quantify their effects on the structural response. Table 6 lists the sources of modeling error that were considered most important to the vessel response. 


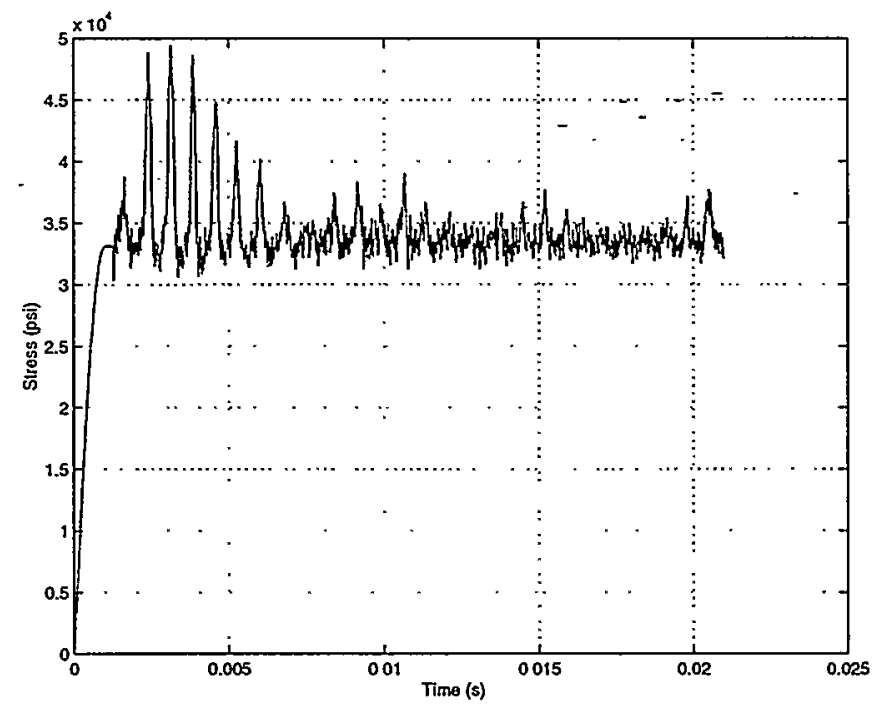

Fig. 28. The axial stress at the midshank of bolt \#1 (10-lb HE, center-initiation load case). Note that the first millisecond of response represents the bolt preload step.
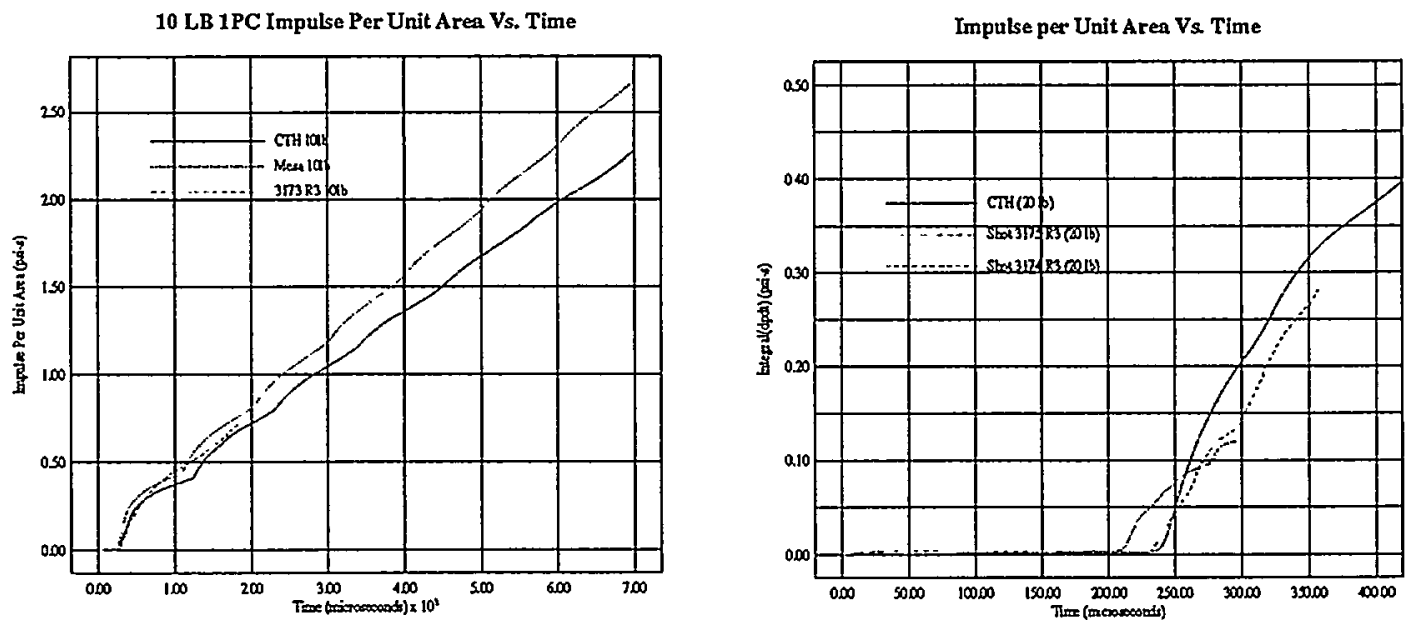

Fig. 29. Comparison of impulse per unit area between experiment and predictions. Left: 10-lb HE load case. Right: 20-lb HE load case. 

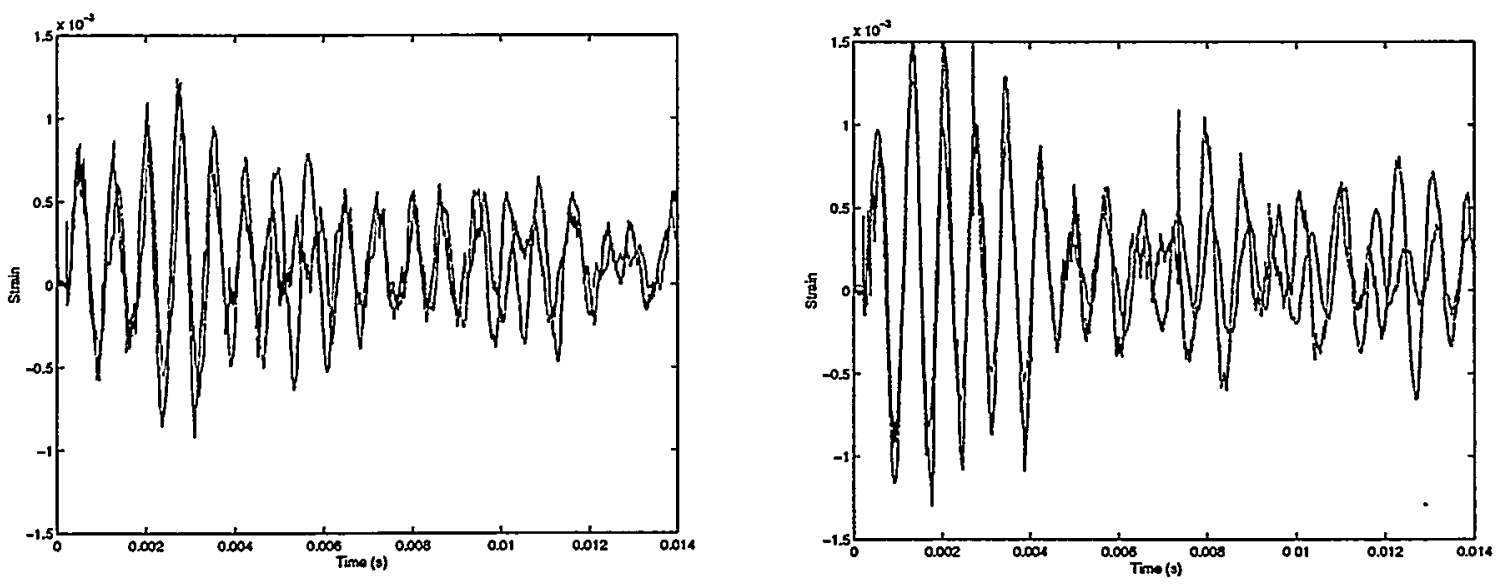

Fig. 30. Comparison of experimental and predicted strains for 20-lb HE load case. Left: strain gauge 2 (near equator of vessel). Right: strain gauge 4 (near south pole). Green line is experimental; blue line is model results.
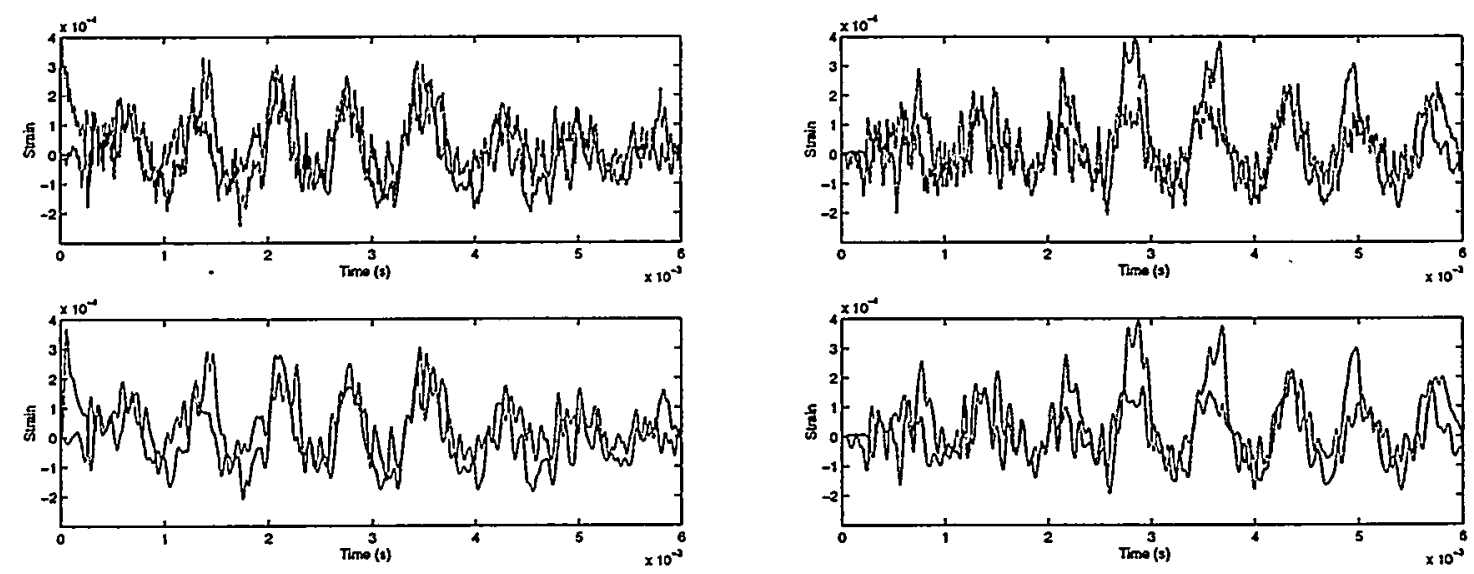

Fig. 31. Comparison of predicted and experimentally measured axial strain for two bolts on the inner bolt circle of the 16-in. port. In each plot, the unfiltered data are shown at the top, and the same data after a low-pass filter was applied are shown at the bottom. 


\section{Table 6: Sources of Modeling Error}

Effect or Un-modeled Feature

1) Variation in vessel wall thickness

2) Variation from bolt to bolt of tightening torque (wrench torque)

3) Variation from bolt to bolt of actual preload achieved, given identical tightening torques

4) Geometric simplifications resulting from tolerance at door-to-nozzle interfaces

5) Friction between doors and nozzles

6) Damping

7) Approximations of the physical phenomena of HE detonation in air

8) Assignment of pressures calculated by the hydrocode

9) Approximations of the physical phenomena of elastic (plastic) structural mechanics

10) Baffle plates in front of 16-in. ports were included in two of the vessel tests $(3173$ and 3174).
The vessel wall thickness is known to vary, to a value of as much as 2.5 in. thick. Furthermore, the thickness variation is not random, but biased (thinner near the 16-in. ports, thicker near the hemisphere-to-hemisphere weld). All models used a constant wall thickness.

Tightening torque will depend on operational details and will vary from shot to shot.

It is the bolt preload, not the tightening torque, that directly affects the joint's behavior under load. A typical standard deviation of bolt preload (for identical tightening torques) is on the order of $14 \%$ of the mean [15]. Preloads varied by more than $17 \%$ from the desired value in tests of the actual vessel [16].

The as-built clearance between door and nozzle (as shown in Fig. 2), as well as the flatness tolerance of the mating surfaces, will vary from vessel to vessel. These tolerances have been shown to affect the bolt loading determined by the models.

The friction model used was simple Coulomb friction, with a value of the single parameter (the "coefficient of friction") of 0.4 . This is a rough approximation of the actual behavior.

Material damping was not included in the model.

Applicability of the equation of state, mesh discretization, and the assumption of axisymmetry are all important approximations.

Blast pressures were calculated at discrete locations by the hydrocode and were assigned on a patch-by-patch basis to the inner surface of the structural model. This assignment scheme is not exact.

Material isotropy and mesh discretization are important approximations.

No baffle plates were included in the hydrodynamic or structural models. 


\section{REFERENCES}

1. K.S. Holian et. al, "MESA: A 3-D Computer Code for Armor/Anti-Armor Applications," in "Proceedings of the Supercomputing World Conference, October 17-20, 1989."

2. E.S. Hertel et. al, "CTH: A Software Family for Multidimensional Shock Physics Analysis," in "Proceedings of the 19th International Symposium on Shock Waves," Volume I, (July 2630, 1993), pages 377-382.

3. R.L. Bell et. al, "CTHGEN Users Guide Version 3.0," Sandia National Laboratories (May 27, 1998).

4. Robert Whirley and Bruce Engelmann, "DYNA3D User Manual," Lawrence Livermore National Laboratory report UCRL-MA-107254, Rev. 1 (Dec. 1998).

5. E.L. Lee et. al, "Adiabatic Expansion of High Explosive Detonation Products," Lawrence Radiation Laboratory report (May 2, 1968).

6. D.E. Lambert et. al, "Characterization of the Hydrodynamic Performance Properties of AFX235 and 65/35 Fine Grain Octol Explosives," Wright Laboratory, Armament Directorate report WL-TR-96-7035 (June 1996).

7. C.W. Cranfill, "EOSPAC: A Subroutine Package for Accessing the Los Alamos Sesame EOS Data Library," Los Alamos National Laboratory Manual LA-9728-M (August 1983).

8. Ernest J. Czyryca, Richard E. Link, Richard J. Wong, Denise A. Aylor, Thomas W. Montemarano, and John P. Gudas, "Development and Certification of HSLA-100 Steel for Naval Ship Construction," Naval Engineers Journal (May 1990).

9. Richard E. Link and Ernest J. Czyryca, "Mechanical Property Characterization of HSLA-100 Steel Plate," David Taylor Research Center report SME-88/38, David Taylor Research Center, Bethesda, Maryland (December 1988).

10. Shuh-Rong Chen, MST-5, "HSLA Experimental Data and Constitutive Modeling," Los Alamos National Laboratory memorandum to Christopher Romero, DX-5 (May 16, 1997).

11. W.E. Baker et. al, "Explosion Hazards and Evaluation," Fundamental Studies in Engineering 5 (Elsevier Publishers, 1983, Chapter 3).

12. M.W. Lewis, T.L. Wilson, "Response of a Water-Filled Spherical Vessel to an Internal Explosion," Los Alamos National Laboratory report, LA-13240-MS (June, 1997).

13. Thomas A. Duffey, "Asymmetric Vibration Modes of Spherical Vessels," Los Alamos memorandum DX-5/98-004 (November 2, 1998).

14. C. Romero and R. Thornton, "HSLA-100 Vessel Test Series Report for Vessel Certification," Los Alamos National Laboratory memorandum DX-5:99/CR-010 (May 1999).

15. Joseph Shigley and Larry Mitchell, "Mechanical Engineering Design," Fourth Edition, (McGraw-Hill Book Co., New York), Chapter 8, 1983.

16. Thomas A. Duffey, "Vessel Closure Bolt Comparisons," Los Alamos National Laboratory memorandum DX-5/99-002 (May 24, 1999). 